\title{
TRATAMIENTO Y GESTIÓN DE LA INFORMACIÓN ARQUEOLÓGICA: ¿UN PROBLEMA O UN RETO?
}

\section{Treatment and management of the archaeological information: a problem o a challenge?}

\author{
Catalina Galán Saulnier* y José L. Sánchez Meseguer**
}

Recibido el 4 de febrero de 2008. Aceptado el 28 de julio de 2008.

Resumen. La utilización de la información arqueológica, tanto la de necesaria consulta, uso y estudio como la generada por la actuación del//a arqueólogo/a en el desarrollo de su trabajo, y tanto en el marco del ejercicio profesional en la investigación histórica propiamente dicha como en el de la comúnmente denominada "arqueología de intervención", e incluso en el de la docencia, supone actualmente un gran reto debido a su gran volumen, su heterogeneidad y la diferente composición de las distintas "unidades" que la constituyen. Este artículo trata de acercar al profesional de la ciencia arqueológica, y muy especialmente a quienes tienen reciente el final de su formación académica, a los problemas que plantea esa información y las soluciones que la Informática ofrece para su tratamiento y gestión mediante las Bases de Datos, los programas de dibujo asistido por ordenador y de tratamiento de imagen, los Sistemas de Información Geográfica y los programas de reconocimiento de formas o los Sistemas Expertos, dentro ya del área de acción de la Inteligencia Artificial, prescindiendo en lo posible de la utilización de términos técnicos y utilizando un lenguaje casi coloquial que haga más cercano el tema a quienes aún no están familiarizados con él o, en su caso, a quienes ya se sientan abrumados y/o preocupados ante los problemas relacionados con la información inherente a la Arqueología.

Palabras clave: Información, Historia, Arqueología, Informática, Arqueomática.

Sumary. The use of the archaeological information, as well as the necessary enquiry, use and study like the generated by the action of the archaeologist in the development of his work, as in the framework of the professional exercise in the historical research in strict sense like in the commonly called "Archaeology of intervention", and even on the teaching, supposes actually a great challenge due to its great volume, its heterogeneity and the different composition of several "units" that constitute it. This article deals with the professional approach of the archaeological science, and particularly anyone who recently finished their academic education, to the problems that this information raises and the solutions that the Computer Science offers for the treatment and management of the Databases, programs for computer-aided design and image processing, the Geographical Information Systems and the recognition of forms with several programs, or the Expert Systems, and within the area of action of Artificial Intelligence, dispensing with the possible of the utilization of technical terms and using an almost colloquial language that makes the topic more nearby to the people who are not yet acquainted with it or, in the case of who feel overwhelmed and / or worried about the problems related to the inherent information in the Archaeology.

Key Words: Information, History, Archaeology, Computer Science, Arqueomatic.

(*) Departamento de Prehistoria y Arqueología. Universidad Autónoma de Madrid. Ctra. de Colmenar Viejo, Km 15. 28049 Cantoblanco. (Madrid).catalina.galan@uam.es

${ }^{* *}$ Coordinador Científico de la Asociación para el Desarrollo del Campo de Calatrava. Cl Arzobispo Cañizares, 6 (Antiguo Almacén de los Fúcares).13710 Almagro (Ciudad Real).sanchezmeseguer@msn.com 
Uno de los rasgos más llamativos de los estudios históricos actuales es, sin duda, la atención que, de no hace mucho tiempo a esta parte, prestan los propios historiadores a los resultados de las investigaciones arqueológicas y, en muchas ocasiones, quizá cada vez más, esa atención se convierte incluso en una auténtica demanda de información una vez que, por fin, parece que la Arqueología ha obtenido un reconocimiento ampliamente generalizado -aunque aún no totalmente- como método de la Historia, por supuesto sin detrimento de su carácter de ciencia, y no sólo cuando la información escrita no existe, sino afortunadamente también cuando ésta no es suficiente $y$, aunque lo sea, siempre que los resultados que proporcione sirvan para contrastar, y en su caso corroborar, los datos aportados por las fuentes históricas tradicionales.

Consecuencia inevitable de ello es la consideración actual de todos los restos culturales como verdaderos documentos del Pasado, ya sean "escritos" o "no escritos" y ya se guarden en archivos, bibliotecas o museos, respectivamente, pero evidentemente y en cualquier caso, tan componentes del Patrimonio Histórico y Cultural como los que se guardan y conservan en pinacotecas o los que per se han merecido la calificación de monumentos.

Hoy es más obvio que nunca que la Arqueología trabaja para la Historia, para todos y cada uno de los periodos que se han diferenciado en ella -Prehistoria, $\mathrm{H}^{\text {a }}$ Antigua, $\mathrm{H}^{\text {a }} \mathrm{Me-}$ dieval, $\mathrm{H}^{\text {a }}$ Moderna, $\mathrm{H}^{\text {a }}$ Contemporánea-, y es así porque la información que proporciona la ciencia arqueológica no sólo es abundante, sino en muchos casos fundamental, cuando no imprescindible, para el mejor conocimiento del Pasado, ya que generalmente la Arqueología acerca más al historiador a la "gente corriente" y al "día a día" de los pueblos que a personajes concretos $y / 0$ a acontecimientos importantes, $y$ porque, hablando también en términos generales, la Arqueología proporciona, no la información contenida en documentos en los que ciertos datos se plasmaron con una intencionalidad evidente, sino, por el contrario, la que contiene lo que quedó en un determinado lugar y de una determinada manera porque alguien lo quiso así pero no dejó constancia expresa de su intención, o bien lo que quedó en un determinado lugar y tal vez "de cualquier manera" precisamente por razones opuestas, es decir, porque nadie lo quería para nada por no ser ya útil, o lo que es lo mismo, por ser lo que ahora denominamos "residuo" y calificamos de "desechable" (y esto sin perder de vista el hecho de que la idea del "reciclaje" también estuvo en la mente del hombre del Pasado).

Parece pues bastante fácil de comprender que la información arqueológica es imprescindible para documentar la Historia, ya que esa documentación es en ocasiones la única utilizable, otras veces complementaria y "en último término", es decir, aun cuando la tradicionalmente considerada como documentación histórica sensu stricto fuese totalmente objetiva, precisa y completa, la información arqueológica siempre cumplirá una importante función: confirmar lo que "dicen" otros tipos de documentos. Y si no es así, está claro que la investigación debe continuar ...

Y está claro que hemos de seguir investigando porque el estudio de cualquier documento del Pasado supone un análisis que desvele sus características, análisis que las tecnologías actuales permiten sea cada vez más completo, preciso y objetivo, pero ese estudio supone también una clara identificación de los resultados del análisis y sobre todo, y este es el quid de la cuestión, una interpretación de los mismos en la que siempre habrá un componente de objetividad ciertamente peligroso si el historiador pretende que la Historia sea un fiel reflejo de la Realidad Pasada, al menos en tanto no sean totalmente autónomas -si es que lo son algún día- esas máquinas que, hoy por hoy, "sólo" sirven para almacenar, relacionar, calcular, representar gráficamente, etc. los datos que previamente el hombre recolecta, aunque lo hagan a velocidades casi infinitamente superiores a la máxima capaz de alcanzar por el más rápido de los seres humanos.

Identificar la propia información, primero, e interpretarla, después. Leer los datos escritos y "leer" los no escritos, primero, y deducir su sentido y razón de ser, después.

Esas son las dos necesidades más imperiosas de la Historia, y de la Arqueología en su parcela de actuación, y son también dos problemas a los que historiadores y arqueólogos de hoy nos hemos de enfrentar animados por las expectativas que nos ofrecen tanto las tecnologías modernas como los planteamientos metodológicos actuales de ambas ciencias, pero también ciertamente abrumados porque unas y otros, sumados a las necesidades de la sociedad en que vivimos, han provocado tal aumento del volumen de información, especialmente en las últimas décadas, que si el investigador ya formado a menudo se plantea si será capaz de "procesarla" obviamente es comprensible que quien comienza su andadura en la investigación del Pasado sienta impotencia, desorientación a en ocasiones, hasta un cierto miedo.

Pero no podemos echarnos atrás. Nosotros mismos, historiadores y arqueólogos, somos los primeros demandantes de más y más información, de datos que arrojen más luz sobre los muchos problemas que plantea el estudio serio y científico del Pasado y que aporten respuestas para tantas y tantas incógnitas que aún se nos plantean, incógnitas cuyo número aumenta continuamente porque los métodos y técnicas que permiten despejar algunas de ellas a menudo aportan también nuevos datos que más bien parecen complicar la propia investigación en vez de contribuir a que llegue a su fin.

Y ante este panorama tal vez no sea malo escuchar a la sabiduria popular, que ha sabido sintetizar problemas y resumir vías de solución, cuando dice que "a grandes males, grandes remedios", que muchas veces "los árboles no dejan ver el bosque" y que "más vale calidad que cantidad". 


\section{LA "CADENA OPERATIVA" DE LA INFORMACIÓN ARQUEOLÓGICA}

Pese a la idea generalizada, y popularizada, de que la actividad arqueológica comienza en el campo -y hoy habría que añadir que también a pie de obra-, el arqueólogo debe ser consciente de que su formación, siempre continua, y su actuación no empiezan realmente alli donde se hallan in situ los objetos materiales de su investigación, los restos culturales, sino en el gabinete de trabajo, personal o de equipo, donde, ineludiblemente el arqueólogo ha de "manejar" una abundante y variada información no generada por él mismo, pero que es una INFORMACIÓN NECESARIA PREVIA a cualquier actuación, ya sea ésta "de campo" o "de gestión", una actuación que siempre ha de ser profesional y de investigación, por más que últimamente se intenten disociar ambos conceptos.

Porque siempre que un arqueólogo actúe como tal ha de hacerlo como un verdadero profesional, aunque la suya no sea una profesión "catalogada", y tanto si su actuación se desarrolla en el marco de la prospección y/o la excavación arqueológicas como si lo hace en el de la docencia y/o la investigación pura, porque si la Arqueología es el estudio de lo antiguo, por principio no habrá nunca Arqueología sin investigación, esté el objeto de estudio - los restos culturalesen el campo propiamente dicho o en lo que su día lo fue, y evidentemente ese estudio ha de llevarse a cabo tras una formación científica y profesional pues, de lo contrario, no se hará Arqueología ...

Y si es cierto que el arqueólogo ha de enfrentarse en primera instancia a una información anterior a su propio trabajo y generada por otros, también lo es que para prospectar, excavar e investigar, que prospectando, excavando e investigando, y que después de la prospección, de la excavación y como colofón de la investigación, el arqueólogo ha de generar, de modo prácticamente continuo, nueva información que inmediatamente se convertirá en necesaria para otros, una información también abundante y variada y que se genera tanto en paralelo al propio trabajo de campo como en los laboratorios y gabinetes en los que ésta ha de completarse.

La actividad arqueológica comienza pues en el gabinete, continúa en "el campo", sigue en el laboratorio y vuelve de nuevo al gabinete, y siempre "manejando" información ... Pero evidentemente hay que concretar: ¿Qué tipo de información?

\subsection{Información NECESARIA}

Tradicionalmente, y esa tradición se ha mantenido hasta hace relativamente poco, la comunidad científica -en general, pero con excepciones- había venido considerando la prospección como una primera etapa del trabajo arqueoló- gico, necesaria pero en cierto modo "prescindible", en tanto que la prospección "sólo" informa sobre lo constatado en superficie 0 , a lo sumo en parcelas muy reducidas del subsuelo si se realizan sondeos, o sobre aspectos muy concretos (presencia/ausencia de estructuras, diferentes tipos de relleno arqueológico, etc.) y siempre dependiendo de la relación entre el número de sondeos y la superficie prospectada y de la metodología y técnicas utilizadas en cada caso, por lo que es obvio que la prospección arqueológica ilustra sobre las características generales de los yacimientos, pero nunca lo hace sobre la totalidad de las específicas de todos y cada uno de sus componentes. En pocas palabras, la prospección ilustra sobre lo que "se ve" o "se visiona", pero a nadie escapa que para conocer es necesario excavar ...

También tradicionalmente se ha considerado la "prospección documental" como etapa necesariamente previa a cualquier investigación arqueológica, pero en honor a la verdad hay que admitir que, también hasta hace relativamente poco tiempo, y por supuesto en términos generales pero no de forma generalizada, esas prospecciones documentales iban encaminadas fundamentalmente a la justificación del planteamiento de la necesidad de llevar a cabo excavaciones arqueológicas en determinados yacimientos y/o de la necesidad de desarrollar trabajos de investigación sobre temas concretos, lo que a menudo conllevaba que esas búsquedas de información en ocasiones no fuesen exhaustivas sino reducidas a lo estrictamente necesario para los fines perseguidos, o incluso a que se hiciesen en el marco de unos límites temporales $y / 0$ espaciales prefijados en función de premisas metodológicas o incluso políticas y/o ideológicas.

Pues bien, hoy no sólo las cosas no son así sino que la prospección documental ha adquirido un gran valor en el amplio abanico de actividades arqueológicas, hasta el punto incluso de ser necesaria su realización para el cumplimiento de la legislación vigente y de alcanzar tal importancia sus resultados como para condicionar actuaciones arqueológicas subsiguientes -nos referimos a los "informes históricos" de la Arqueologia "de gestión"-, y es al llevar a cabo esa necesaria labor cuando el arqueólogo se enfrenta al "manejo" de una información extremadamente diversa en su formato y en su contenido, una información que requiere un tratamiento metodológicamente planificado y enfocado a obtener la mayor cantidad posible de datos, a permitir su valoración y posterior selección, y a utilizarla como base en la que apoyar la metodología a seguir en las actuaciones a desarrollar a continuación, ya sean éstas trabajos de investigación sobre los datos seleccionados, prospecciones sobre el terreno, excavaciones arqueológicas o simplemente seguimientos de obra.

$Y$ de la diversidad de formatos y contenidos de esa INFORMACIÓN PREVIA a cualquier actuación arqueológica darán buena fe quienes recuerden los "trabajos de curso" de su época de estudiantes aunque incluso ya licenciados, no se 
hayan enfrentado aún a la elaboración de su primer proyecto de intervención arqueológica, de su trabajo de doctorado o de su tesis doctoral, porque ya en la etapa de su formación debieron "manejar" varios tipos de documentos que, en aras de la mejor comprensión del problema, se pueden agrupar en los siguientes conjuntos:

- Información histórica sensu stricto: fuentes de información cuyo carácter de "escritas" les confiere la consideración tradicional de "documentos históricos propiamente dichos";

- Información literaria, contenida en diversos tipos de obras (novelas, libros de viajes, cuentos, cartas, artículos, etc.) en las que aparecen menciones a personas, lugares, edificios, objetos, hechos, costumbres, modos de vida, etc. que a menudo suponen un buen complemento de la información histórica propiamente dicha;

- Información administrativa, generada por las Administraciones Públicas, de diferentes clases o tipos y con diferentes funcionalidades (catastros, relaciones topográficas, catálogos de explotaciones mineras, cartas e inventarios arqueológicos, legislación vigente, etc.);

- Información iconográfica de diversas clases y caracteristicas, desde la contenida en representaciones artísticas (personas, hechos, edificios, objetos, lugares, paisajes, etc.), a la información planimétrica (planos generales y/o parciales, secciones topográficas y/o estructurales y/o estratigráficas, etc.), cartográfica (representación gráfica de la forma y ubicación espacial de lugares, construcciones, vías de comunicación y otros componentes naturales y artificiales del paisaje) y fotográfica (imágenes de origen diverso, en diferentes formatos y tomadas con distintas finalidades);

- Información arqueológica, resultado del estudio de los restos culturales y tan variada como ellos mismos y la propia actividad arqueológica (epigráfica, numismática, "bibliografía específica", trabajos inéditos, etc.); y por último,

- Información de otras Ciencias de alguna forma relacionadas con la Arqueología. Actualmente esta relación se extiende a numerosos campos del saber, por lo que su cantidad y variedad (información geológica, paleontológica, edafológica, relativa a la aplicación de técnicas analíticas, etc.) también han adquirido un considerable volumen y unas características particulares.

\subsection{Información GENERADA}

Inmediatamente después de esa búsqueda documental, la Arqueología empieza a generar nuevos tipos de informa- ción, ahora tan abundante y variada como la propia actividad arqueológica lo es.

Teniendo en cuenta que actualmente esa actividad se dirige básicamente en dos direcciones, las generalmente denominadas "arqueología de gestión" y "arqueología de investigación", lógicamente se observa que la información generada en ambos casos tiene diferentes formas y contenidos, los cuales no recogen los mismos tipos de datos ni comparten los mismos modos de presentación, al tiempo que son destinados a "usuarios" diferentes.

La "arqueología de gestión" genera una información cuyas características vienen "prediseñadas" por una serie de parámetros que poco o nada tienen que ver con la ciencia arqueológica, quedando a merced de la profesionalidad del arqueólogo su calidad y validez científicas, y no se puede olvidar al respecto que la Arqueología es una ciencia, y que la práctica arqueológica "de gestión" no es sino su aplicación a determinadas necesidades sociales.

Es más. Esos factores que determinan las caracteristicas de este tipo de información tienen a su vez orígenes diferentes, como diferentes son los fines que han de perseguir los distintos tipos de documentos emanados.

La legislación vigente obliga a elaborar un "informe histórico" y/o "paleontológico" previo a cualquier intervención arqueológica, cuya finalidad a priori es suficientemente clara: el patrimonio arqueológico es parte del Patrimonio Cultural, y por tanto cualquier actuación que requiera un estudio de su presunto impacto ambiental requiere un informe previo sobre las características del patrimonio arqueológico que presumiblemente pueda ser afectado (clasificación cultural y cronología, estado de conservación y de investigación, etc.).

Ahora bien, es obvio que ante esta situación la viabilidad de una determinada actuación y el tipo de "medidas correctoras" que en su caso requiera, dependen - o, a favor de la realidad, mejor deberían depender - de lo recogido por el arqueólogo responsable en el correspondiente "informe histórico", por lo que queda totalmente a merced de su ética profesional la "calidad" y la "cantidad" de información incorporada al mismo, e incluso la forma de su presentación, pues de ello puede depender el tipo de actuación arqueológica a realizar -y el "arqueólogo de gestión" vive de las actuaciones arqueológicas de obligada realización-, una vez que la Administración, quien a su vez debe controlar la calidad de esos informes, se haya pronunciado sobre el tipo de intervención arqueológica a desarrollar, algo evidente y muy directamente relacionado con el costo económico de la misma.

Y si en las características de esos "informes históricos" influyen tantos factores externos al propio problema arqueológico a que se refieren, qué decir de otros tipos de documentos generados por la "arqueología de gestión" antes de su actuación directa, como los "proyectos de interven- 
ción", en los que en ocasiones el arqueólogo, que también ha de tener muy presentes los condicionantes económicos, no puede ni siquiera proponer una metodología de trabajo diseñada en función de lo recogido en el informe histórico previo, porque es la propia Administración quien le impone qué hacer y como hacerlo...

Pero las cosas son muy diferentes cuando se trata de la información generada por la "arqueología de investigación", una información cuyos contenidos están relacionados con problemas históricos aún sin resolver que se investigan generalmente, o al menos en numerosas ocasiones, en dos tipos de "marcos" a menudo intercomunicados, los Proyectos de Investigación y las Tesis Doctorales, y cuya presentación "adquiere" formas diferentes (libros, artículos, ponencias y comunicaciones a congresos/simposios/mesas redondas, etc.) pero con un "denominador común": dar a conocer esa información y ponerla a disposición de la sociedad en general y de la comunidad científica - de la que indudablemente no queda excluido el arqueólogo "profesional"-, en particular.

Bien es cierto que muchas veces la realización de las tesis doctorales se ve condicionada por factores económicos, como también los propios soportes de publicación, pero con todo, y aún teniendo en cuenta que también las ideologías, las escuelas, e incluso determinadas posturas personales, influyen en las caracteristicas de esa información generada por la investigación arqueológica, pero también lo es que, en general, su gran "defecto", o mejor, su rasgo que más puede "asustar" al arqueólogo que haya de "manejarla" es el ser demasiado abundante y variada en muchos sentidos, el denotar una evidente falta de unidad de criterios ya se trate de elaborar "estados de la cuestión", "catálogos", "metodologías", "síntesis", "conclusiones" o estudios monográficos, fruto sin duda de la diversidad de esa comunidad científica en la que, como en el ámbito de la "arqueología de gestión", no todos los profesionales lo son en el mismo grado.

Y el trabajo continúa.

En el momento en que comienza la intervención arqueológica directa, ya sea a modo de trabajo "de campo", gabinete o biblioteca, la Arqueología sigue generando una información que queda recogida y organizada en inventarios, diarios, informes, planimetrías, cartografías, fotografías, etc. cuyo formato y características dependen ahora del saber hacer del arqueólogo responsable en cada caso, si bien, como es sabido, él mismo no siempre puede poner en práctica la metodología de trabajo que considere más conveniente, bien porque su trabajo se desarrolle en el marco de un proyecto de investigación en el que esa metodología ha sido diseñada previamente por la dirección del mismo, bien porque trabaje con una empresa que imponga su propio modus operandi, a menudo pese a que la responsabilidad científica de la propia excavación arqueológica recaiga directamente sobre el/la directora/a del mismo, es decir, sobre el/la arqueólogo/a a quien la Administración ha autorizado su dirección.

A menudo la siguiente etapa de la actuación arqueológica se centra en lo que genéricamente se puede denominar "trabajo de laboratorio", bien entendido que esta denominación se refiere a todas aquellas tareas relacionadas con la manipulación de los restos culturales, independientemente de las caracteristicas específicas de los diferentes laboratorios y/o gabinetes por las que éstos vayan pasando hasta su definitivo depósito en el museo correspondiente. Ese es el momento en el que la Arqueología empieza a generar una gran cantidad de información relativa a las características de esos restos (descripciones tecnológicas y morfológicas, analíticas), su estado de conservación (diagnósticos, tratamientos), etc., así como un gran volumen de documentación de diversa índole (inventarios, dibujos, fotografías), todo lo cual hace que dicha información sea tan variada en cuanto a su formato como lo son las metodologías al uso y que su calidad y validez, de las que de nuevo es científicamente responsable el/la arqueólogo/a a quien la Administración concedió el permiso de excavación, en ocasiones sin tener demasiado en cuenta su formación, experiencia y especialización profesionales, sean también diferentes.

Y finalmente el arqueólogo que comenzó su trabajo en el gabinete, vuelve a él para enfrentarse al tratamiento y la gestión de toda esa información que ha ido acumulando, la necesaria para acometer su trabajo y la generada en el transcurso del mismo, y lo hace para generar aún más, para elaborar una documentación que de nuevo presenta rasgos muy diferentes en esos "sectores" de la actividad arqueológica hoy denominados "arqueología de gestión" y "arqueología de investigación".

Evidentemente todos los factores que determinan las distintas actuaciones arqueológicas e influyen en su desarrollo lo hacen también en la última de ellas: la plasmación de los resultados obtenidos en forma de Cartas Arqueológicas, Inventarios Arqueológicos, Memorias, tesis Doctorales y todo tipo de publicaciones.

Ahora bien, nuevamente hay que tener en cuenta que toda esa información generada en último término por la actividad arqueológica y que, como ya indicamos, se convierte desde el momento en que se hace pública en la principal "fuente de alimentación" de la propia actividad, es inmensamente abundante y variada, aunque también es cierto que el arqueólogo no siempre tiene la posibilidad de "manejarla" en su totalidad, ya que si el acceso a lo que está publicado no tiene más límite que el tiempo y los medios materiales disponibles para ello, sin embargo el acceso a lo no publicado en libros, revistas, actas de congresos y simposios, etc. a menudo, y pese a ser documento público por haber sido entregado a la Administración en cumplimiento de la normativa legal vigente, es restringido o incluso denegado por la propia Administración en función de argumentos basados en 
una no bien entendida forma de salvaguardar el Patrimonio Arqueológico manteniendo "en secreto" alguna o algunas de sus características, o de valoraciones que, lógicamente, nunca deberían contradecir la realidad basada en una información objetiva, aunque con frecuencia lo hacen.

En cualquier caso, tampoco se puede ignorar que si el contenido y la forma de esas cartas e inventarios arqueológicos y de los informes y memorias derivados de los trabajos desarrollados en el marco de la "arqueología de gestión" tienen todas las condicionantes señaladas en las líneas precedentes, su propia realización también está condicionada por factores tan ajenos a la verdadera Arqueología como los limites temporales y económicos derivados del hecho de tratarse de trabajos derivados a su vez de intervenciones arqueológicas llevadas a cabo en marcos contractuales, o la posibilidad de que del resultado de unas intervenciones arqueológicas pueda depender la realización de otras, ya que es evidente que el arqueólogo puede sentirse presionado al elaborar una documentación de cuyo contenido depende la viabilidad y/o el coste económico de determinados proyectos a realizar como consecuencia.

$Y$ ante este cúmulo de comentarios surge una pregunta inevitable: ¿qué tipos de datos componen realmente ese conjunto que venimos denominado "información arqueológica"?

Parece bastante evidente que el conocimiento de las caracteristicas de los componentes ha de ser la base a partir de la que decidir qué hacer con el conjunto ...

\section{DATOS "VARIOPINTOS Y MULTICOLORES"}

El desarrollo de la propia ciencia arqueológica y su relación con otras ciencias y técnicas, cada vez más compleja y prometedora, ha convertido a la Arqueología en una inagotable "factoría de datos" que, como un gran chorro de luz, van iluminando cada vez con más fuerza el Pasado de la Humanidad, permitiendo así "ver" cada vez con más claridad cómo fue su verdadera historia, aunque muchos aspectos quedan aún en penumbra y otros en una total oscuridad.

$Y$ como es sabido, cuando el humano quiere conseguir un escenario lo más próximo a la realidad que sea posible en el oscurecido ambiente de un teatro, un estudio cinematográfico o un plató de televisión, necesita utilizar luces de diferentes tamaños, colores e intensidades. Pues valga el simil para explicar por qué la Arqueología necesita la mayor cantidad y variedad posible de datos: todos arrojan luz pero de diferente forma.

"Traducida" la comparación al problema objeto de estas líneas, es fácil deducir que el arqueólogo se enfrenta a una información constituida por un gran volumen de DATOS DE TRES CLASES, ALFANUMÉRICOS, NUMÉRICOS Y GRÁFICOS, identificables en función de la forma en que se presentan: textos, cifras y representaciones gráficas/imágenes.

\section{3. "A GRANDES MALES, GRANDES REMEDIOS"}

Esa información diversa, plural y de composición compleja, genera una serie de NECESIDADES DE CARÁCTER GE$N E R A L$, es decir, que se presentan cada vez que se inicia una actuación arqueológica, sea esta del tipo que sea, que lo hacen siguiendo siempre la misma secuencia y que son:

$1^{\circ}$. Localizar la información;

2․ Capturar la información;

$3^{\circ}$. Sistematizar la información, lo que a su vez supone dos necesidades básicas, objetivary uniformizar los datos que la componen;

$4^{\circ}$. Controlar su situación, en tanto que procesos históricos semejantes se han desarrollado de diferentes maneras cuando han sido diferentes sus respectivos marcos espaciales y temporales, lo que evidentemente supone la necesidad de controlar la ubicación espacial (georreferenciación) y temporal (cronología) de los datos constitutivos de la información arqueológica;

5. Analizar la información;

$6^{\circ}$. Sintetizar la información;

$7^{\circ}$. Interpretar la información y

8. Presentar la información.

El gran volumen de esa información y la diversidad de sus características hacen que a menudo esas necesidades se conviertan en verdaderos problemas para el arqueólogo, pero problemas para los que hoy las tecnologías de la información ofrecen múltiples soluciones mediante el uso de unas herramientas que el propio profesional de la Arqueología puede manejar o que, en su caso, puede conocer fácilmente, lo que permite su utilización por personas ajenas a la Arqueología pero bajo la dirección y control de quien realmente se enfrenta a esos problemas y ha de interpretar el resultado de su resolución.

\subsection{Herramientas de tratamiento y gestión de la información arqueológica}

Por razones obvias no se describirán aquí las características técnicas del amplio abanico de herramientas que la Informática ofrece a la Arqueología, dado que la finalidad de estas páginas es "iluminar el camino" de los arqueólogos y arqueólogas noveles, de quienes nada más obtener su licenciatura emprenden su actividad profesional "de gestión" y/o "de investigación", y en un primer momento se ven, o al menos pueden verse, algo abrumados o incluso agobiados por la cantidad y las características de la información que han de "manejar" y de la que ellos mismo empiezan inmediatamente a generar. 
Quienes a lo largo de sus estudios de Licenciatura han entrado en contacto con la aplicación de herramientas informáticas a los estudios históricos, evidentemente pondrán en práctica de inmediato sus conocimientos, pero aún hoy el uso de la Informática no está tan extendido entre los alumnos universitarios como para dar por supuesto que esa es una situación generalizada pues, en el mejor de los casos, y por supuesto salvo las excepciones que siempre existen, la mayoria de los estudiantes de Historia apenas utilizan el ordenador para algo más que para dotar a sus trabajos de curso de un más o menos cuidada presentación, aunque curiosamente, no es raro que lo utilicen también, y a menudo con gran habilidad, como instrumento de ocio más que de trabajo, y a pesar de que los programas -el software- son cada día más accesibles al usuario no experto en Informática gracias al esfuerzo impagable de los que sí lo son y que son también responsables no sólo de que sus "productos" sean herramientas de trabajo muy útiles, hoy indispensables, para la Arqueología, sino incluso de que el arqueólogo pueda elegir la más conveniente en función de sus necesidades y hasta la que mejor se adapte a sus gustos y habilidades personales.

En base pues a este planteamiento y atendiendo a las necesidades generales del trabajo arqueológico a que antes nos referimos, relacionadas tanto con la información necesaria para su ejecución como con la que emana de esa actividad, cabe ahora hacer "un alto en el camino" para observar que, para solucionar esos problemas la Informática ofrece dos grandes grupos de herramientas, las de tratamiento de la información y las que permiten su gestión, herramientas que a su vez han posibilitado que la primera de aquellas necesidades generales, la propia localización de la información, sea cada vez más fácil de cubrir en tanto que cada vez son más los fondos documentales (archivos, bibliotecas, museos) informatizados, y sin olvidar la gran plataforma de búsqueda, localización y captura de información que supone Internet cuyas primeras ventajas al respecto puede comprobar el lec- tor por sí mismo buscando información sobre los conceptos, temas y aplicaciones que trataremos a continuación.

Pero quizá estas palabras conllevan el planteamiento de una pregunta que resulta totalmente lógica: ¿por qué es necesario someter la información a un tratamiento previo a su gestión, o, en definitiva, a su utilización?

Y aunque pueda resultar algo extraño, la respuesta está en la propia lista de necesidades observadas, porque la información que el arqueólogo puede localizar y capturar es, o bien la generada y presentada por otros, o bien la localizada por él mismo en los propios yacimientos arqueológicos y en y ante los propios restos culturales, lo que explica, en ambos casos, la necesidad de sistematizarla, es decir, de dotarla de la mayor objetividad y uniformidad posibles para que los datos que la componen puedan ser contabilizados, comparadas, ordenados, etc., operaciones difícilmente realizables si los datos no son objetivos y su formato de presentación no es uniforme.

Pues bien, tal y como se representa en la Tabla 1, ese TRATAMIENTO DE LA INFORMACIÓN es posible mediante el uso de las herramientas adecuadas.

Y una vez localizada/elaborada, capturada y convenientemente sistematizada, esa información ya está disponible para ser gestionada por el arqueólogo, una operación que, en lenguaje cotidiano, supone dar respuesta a una pregunta que indefectiblemente surge como consecuencia de su gran volumen y diversidad: ¿qué se puede hacer con todo "eso"? ... Al arqueólogo se le siguen plantando las necesidades generales no resueltas aún, y ¿cómo cubrirlas?

Pues de nuevo la Informática oferta herramientas para facilitar ese trabajo, tal y como se ha sintetizado en la Tabla 2.

Que la información arqueológica es muy abundante y compleja es cierto, pero también lo es que ante los profesionales de la Arqueología se abre hoy un amplio abanico de posibilidades que no sólo le permiten resolver de distintas

Tabla 1

\begin{tabular}{|c|l|l|}
\hline Tipo de información & \multicolumn{1}{|c|}{$\begin{array}{c}\text { Clases de programas } \\
\text { (software) }\end{array}$} & \multicolumn{1}{c|}{ Aplicación } \\
\hline \multirow{2}{*}{ Textual } & Editores de texto & Confección de documentos de texto con formatos de presentación. \\
\cline { 2 - 3 } & Editores de hipertexto & $\begin{array}{l}\text { Confección de documentos de texto con formatos de presentación uniformes } \\
\text { o no, pero relacionados entre sí y/o con documentos gráficos. }\end{array}$ \\
\hline \multirow{2}{*}{ Gráfica } & Programas de dibujo (2D) & $\begin{array}{l}\text { Representación gráfica plana (2D) de la realidad y/o interpretación de la mis- } \\
\text { ma con/sin información adicional. }\end{array}$ \\
\cline { 2 - 3 } & $\begin{array}{l}\text { Programas de diseño } \\
\text { gráfico (3D) }\end{array}$ & $\begin{array}{l}\text { Representación gráfica tridimensional (3D) de la realidad ajustada a sus co- } \\
\text { rrespondientes parámetros (dimensiones reales, localización geográfica exac- } \\
\text { ta) con/sin interpretación de la misma y/o informacional adicional. }\end{array}$ \\
\cline { 2 - 3 } & $\begin{array}{l}\text { Programas de tratamiento } \\
\text { de imagen }\end{array}$ & $\begin{array}{l}\text { Manipulación de imágenes (fotografias, diapositivas, imágenes digitales, ví- } \\
\text { deo) con diversas finalidades (uniformización de formatos dimensionales, de } \\
\text { color, etc.) con/sin adicción de datos interpretativos y/o complementarios. }\end{array}$ \\
\hline
\end{tabular}


Tabla 2

\begin{tabular}{|c|c|c|c|}
\hline Necesidades generales & Necesidades implícitas & $\begin{array}{l}\text { Clases de programas } \\
\text { (software) }\end{array}$ & Aplicación \\
\hline \multirow{5}{*}{ Analizar } & Almacenaje & \multirow{4}{*}{ Bases de datos (BD) } & \multirow{4}{*}{$\begin{array}{l}\text { Almacenaje sistematizado de la informa- } \\
\text { ción que permite la ordenación, selección, } \\
\text { relación, etc. de los datos que la compo- } \\
\text { nen y su posterior gestión mediante pro- } \\
\text { gramas de SIGA }\left({ }^{*}\right) \text { e IA }\left({ }^{* *}\right) \text {. }\end{array}$} \\
\hline & Ordenación & & \\
\hline & Selección & & \\
\hline & Relación & & \\
\hline & Cálculo & Hojas de Cálculo & $\begin{array}{l}\text { Resolución rápida de operaciones mate- } \\
\text { máticas con todos/agunos de los datos } \\
\text { numéricos almacenados en } \mathrm{BD} \text {. }\end{array}$ \\
\hline \multirow{3}{*}{$\begin{array}{l}\text { Controlar situación } \\
\text { (tiempo y/o espacio) }\end{array}$} & $\begin{array}{l}\text { Correlación datos } \\
\text { temporales - datos } \\
\text { espaciales }\end{array}$ & \multirow{3}{*}{$\begin{array}{c}\text { Sistemas de Información } \\
\text { Geoarqueológica (SIGA) }\end{array}$} & \multirow{3}{*}{$\begin{array}{l}\text { Georreferenciación de la información ar- } \\
\text { queológica (localización espacial), pun- } \\
\text { tual/por áreas, observación, análisis y va- } \\
\text { loración de la relación, información } \\
\text { arqueológica, información geográfica, } \\
\text { otros tipos de información (en su caso), } \\
\text { generación y predicción de modelos, etc., } \\
\text { y vsualización diversificada de esas rela- } \\
\text { cionales y modelos. }\end{array}$} \\
\hline & Valoración & & \\
\hline & Predicción & & \\
\hline Interpretar & \multirow{4}{*}{$\begin{array}{c}\text { Todas las "necesidades" } \\
\text { generales previas }\end{array}$} & $\begin{array}{c}\text { Programas de Inteligencia } \\
\text { Artificial (IA) }\end{array}$ & $\begin{array}{l}\text { Resolución probabilística de problemas ar- } \\
\text { queológicos en base a los datos y situa- } \\
\text { ciones conocidos. }\end{array}$ \\
\hline \multirow{3}{*}{ Presentar } & & Editores de texto & \multirow{3}{*}{$\begin{array}{l}\text { Presentación total/parcial de la informa- } \\
\text { ción recolectada y/o generada, en diversas } \\
\text { modalidades y según los requerimientos o } \\
\text { según las necesidades }\end{array}$} \\
\hline & & Editores de Hipertexto & \\
\hline & & Programas de Presentación & \\
\hline
\end{tabular}

formas aquel problema de qué hacer con ella, sino además una también amplia oferta de opciones que, por las características de esa información, no estarían a su alcance si no fuese gracias a la Informática, de tal modo que utilizando las herramientas que esta ciencia ofrece, el arqueólogo puede afrontar no solamente los problemas que le plantea la información que necesita y la que él mismo genera, sino que puede enfrentarse también a un "todo" más complejo aún constituido por esos dos tipos de información sumados a los "productos" de la gestión de ambas, es decir, a un Sistema Integrado de Información Arqueológica (SIA).

\subsection{Sistematización y gestión de los datos arqueológicos: las Bases de Datos. ¿Cómo elegir?}

Como venimos repitiendo insistentemente, muchas y diversas son las características de la información que indefectiblemente ha de manejar quien trabaja en el ámbito de la Arqueología: necesaria, generada, variada, antigua, moderna, dispersa, sintetizada ...

$Y$ tan cierto es esto como que, en realidad, a lo que el arqueólogo se enfrenta es a un gran conjunto de documentos de muy diversa índole, cada uno de los cuales constituye una
UNIDAD DE INFORMACIÓN (en adelante UI) que siempre habrá de ser consultada, analizada y estudiada, y en su caso utilizada, de forma individualizada y con fines diferentes.

Parece bastante obvio que entre la información necesaria para el desarrollo de la actividad arqueológica, todo documento histórico, ahora en el sentido literal del término, con información relativa a personas, lugares, objetos, edificios, fechas, hechos, etc., cualquier soporte icnográfico de información -ya sea un cuadro, un mapa, un plano, una fotografía-, los grandes corpus de carácter fundamentalmente administrativo (catastros, relaciones topográficas, catálogos de explotaciones mineras, inventarios y cartas arqueológicos, etc.) a los que ya nos referimos en su momento, y cualquier publicación de temática específica, son per se UI individualizadas de formato y contenido diversos, y evidentemente también es obvio que participan de esa misma condición el Informe Histórico, el Proyecto de Intervención, el Informe Previo, la Memoria Final, la Tesis Doctoral y cualquier trabajo al que de una u otra forma pueda tener acceso el colectivo de arqueólogos e historiadores.

Ahora bien, evidentemente la información arqueológica es realmente un conjunto constituido no sólo por esos documentos, por esas UI, sino también por otros que sin lugar a dudas participan del mismo carácter de documentos his- 
tóricos como lo son todos y cada uno de los restos culturales, desde el gran monumento al más pequeño grano de polen, que en consecuencia también son per se Unidades de Información aunque no siempre fácilmente "legibles", inteligibles e interpretables, y constituidas por datos que, correspondientes a sus rasgos intrínsecos y extrínsecos, la Arqueología "materializa" en diferentes formatos, unas veces numéricos (resultados de determinadas analíticas, coordenadas, dimensiones, etc.), otras alfanuméricos (descripciones textuales, análisis, estudios, interpretaciones, etc.) o gráficos (dibujos, fotografías, planos, mapas temáticos, representaciones estadisticas, etc.).

En definitiva pues, todo se traduce en que el arqueólogo se enfrenta a un gran volumen de información compleja y variada porque está constituida por una gran cantidad de datos de diferentes clases que el propio arqueólogo necesita almacenar, ordenar, clasificar, seleccionar, relacionar $y$, por supuesto, aumentar a medida que avanza su actividad, es decir, un voluminoso y variado conjunto de datos que el arqueólogo debe tratar y gestionar.

Y para éste, que es sin duda uno de los grandes problemas de la Arqueología actual, las Bases de Datos (en adelante BD) se han convertido en herramienta indispensable de trabajo para la Arqueología y para la Historia, como para tantas otras ciencias.

Evidentemente no es éste lugar para explicar detalladamente qué son ni para qué sirven las $\mathrm{BD}$, ni tampoco sus múltiples aplicaciones a la Arqueología, sobradamente conocidas por innumerables publicaciones fácilmente localizables en Internet, pero a quienes llevamos ya muchos años utilizándolas en nuestro trabajo profesional e investigador, la experiencia adquirida nos lleva a exponer ahora unas cuantas reflexiones que esperamos sean útiles a quienes se inicien en su uso.

Es de sobra conocido que el mundo de las BD ofrece una amplia gama de posibilidades que, en términos genéricos, en terminología más coloquial que técnica y atendiendo a la finalidad de estas páginas, se pueden agrupar en dos grandes bloques: por una parte, las que "aparecen" ante el usuario como lenguajes de programación con los que confeccionar un programa "a medida", y por otra las que se adquieren ya en forma de programas estructurados, para cuyo diseño se han tenido en cuenta unas determinadas necesidades y en consecuencia se han organizado las correspondientes soluciones.

En contadas ocasiones el profesional de la Arqueología lo es también de la Informática o puede trabajar en estrecha colaboración con profesionales de esta ciencia.

Generalmente, por formación, y en razón de los medios materiales disponibles, el arqueólogo entra a formar parte, más tarde o más temprano y en mayor o menor medida, del cada vez más amplio grupo de usuarios de las tecnologías de la información, y la oferta de programas de BD que actual- mente existe en el mercado (ACCESS, OPEN ACCESS, FILEMAKER, etc.) es amplia, variada y más que suficiente para satisfacer las necesidades de la Arqueología, e incluso para permitir que el investigador elija el programa más adecuado a sus necesidades, una elección en la que indudablemente influirán la formación y las preferencias personales.

Pero, en cualquier caso, el arqueólogo debe optar por programas de BD que le permitan realizar, y lo más cómodamente posible, las siguientes operaciones:

- Diseñar:

- Fichas/Registros para cada UI:

* cuyo formato se adapte a las peculiaridades de éstas y de las necesidades que planteen el tratamiento y la gestión de sus datos,

* que puedan contener diferentes tipos de datos (textuales, numéricos, gráficos,), y

* que permitan introducir, contabilizar, modificar, seleccionar, ordenar, aumentar, etc. datos y UI cómoda, uniforme y fácilmente.

- Informes, Listados, Tablas de valores, etc., según las necesidades:

* a partir de todos los registros/fichas ("continentes") de los datos ("contenido") de las UI, o bien

* a partir de los escogidos en función de uno o varios criterios de selección.

- Modificar el diseño de las fichas/registros, verdaderas "armazones" de las UI en cuyas "partes" se "sitúan" los datos almacenados, según las necesidades.

- Almacenar:

- un gran número de datos correspondientes a

- un gran número de UI.

- Gestionar los datos (consultar, buscar, ordenar, seleccionar, calcular valores, etc.) cómoda y fácilmente.

- Relacionar los datos con:

- los datos de otras BD y con

- el espacio.

Porque esto es posible, porque hay en el mercado suficiente oferta para solucionar esas necesidades, afortunadamente para el arqueólogo de hoy las BD son una herramienta accesible, tanto económicamente como por lo que respecta a su manejo, e imprescindible para la Arqueología actual, una ciencia ya suficientemente "madura" para aportar gran cantidad de importante información a la Historia, y en consecuencia al Patrimonio Cultural.

La Arqueología es hoy una ciencia íntimamente relacionada con disciplinas correspondientes a muy distintos campos del conocimiento (Historia, Biología, Física, Química, etc.), lo que exige su continua actualización $y$, en consecuencia, la de sus planteamientos, y a la que actualmente, 
más que nunca, la sociedad demanda múltiples actuaciones rápidas y efectivas cuyos resultados deben incorporarse rápidamente a su base de conocimientos para actualizarlos, y que exigen análisis, diagnósticos, tratamientos $y$, en su caso, intervenciones que la mayoría de las veces se califican de urgencias ya antes de constatar sus características concretas y para las que la propia sociedad exige un desarrollo en marcos presupuestarios con costos económicos lo más reducidos posible, lo que lógicamente a su vez está intimamente relacionado con el planteamiento de los límites temporales del trabajo no en función de la optimización de los resultados científicos a obtener, sino en función de la minimización del coste económico de dicha intervención.

Las BD son por tanto herramientas más que útiles para hacer frente a esa situación, pero el arqueólogo ha de ser consciente también de que los problemas que le puede plantear la información que necesita y la que él mismo genera no se plantean solamente en términos de "cantidad" "variedad".

Los datos identificativos de un trabajo publicado, una unidad de excavación, un resto cultural, un documento gráfico, etc. en realidad son términos, cifras, gráficos e imágenes que, agrupados en UI ("ficha bibliográfica", "ficha de inventario", "ficha descriptiva", "ficha de archivo fotográfico", etc.) que contienen la expresión materializada de las VARIABLES CUANTITATIVAS y CUALITATIVAS, y sus correspondientes VARIANTES, que caracterizan a esas publicaciones, yacimientos arqueológicos, restos culturales 0 archivos documentales respectivamente, lo que indefectiblemente a la hora de utilizar las BD como almacenes de información accesibles y operativos para el tratamiento y la gestión de la misma, obliga a plantearse, para su diseño y para la efectividad, facilidad y comodidad de su uso, no sólo el carácter cuantitativo/cualitativo de esas variables, sino también el número y el carácter de las respectivas variantes conocidas, cuáles son excluyentes entre sí, e incluso, siendo consciente de que nuestro conocimiento del Pasado aún es limitado, la posible existencia de variables y variantes hoy desconocidas.

En consecuencia, las BD son una gran solución para un gran problema de la Arqueología actual, una solución que sustituye a los antiguos ficheros y archivos de documentación escrita y gráfica por sus evidentes ventajas en cuanto a capacidad y ahorro de tiempo y de trabajo, porque evidentemente su utilización implica también la sistematización automática de ciertos datos, y que incluso permite la aplicación de ciertos criterios estéticos a su diseño que sin duda contribuyen a facilitar y hacer más agradable el trabajo, a menudo tedioso, de almacenar datos y contribuyen también a la mejora de la calidad de la visualización y presentación de los mismos. Pero además, y si lo anterior es importante, esto es fundamental, sin ellas no es posible gestionar debidamente una información con tal volumen de datos de las caracteristicas de los arqueológicos, y al hablar de gestión de la información no nos referimos solamente a la realización de re- cuentos y cálculos estadísticos -normalmente posibles desde el propio software de las BD o utilizando éstas como "plataformas" sobre las que pueden actuar otros programas específicos (hojas de cálculo, programas de estadistica, etc.), sino también a la utilización de esos datos en aplicaciones tan útiles hoy a la Arqueología como las derivadas de otras "ofertas" de la Informática: los Sistemas de Información Geográfica (SIG/GIS) y la Inteligencia Artificial (IA).

Pero el verdadero reto no es su utilización, sino el propio conocimiento de la información que contienen, y si el arqueólogo no conoce bien esa información, mal sabrá qué problemas le plantea, qué "preguntas" debe formular a las UI, cuántas y cuáles serán las posibles "respuestas" que éstas le proporcionen y si esas "respuestas" serán o no, siempre $o$ a veces, excluyentes entre sí como datos de una misma UI o al relacionar UI diferentes, y entonces ... Mal podrá el arqueólogo diseñar "el almacén" si no sabe bien qué va a almacenar, cómo y por qué ordenarlo de determinada manera, como clasificarlo, contabilizarlo, etc., es decir, qué va a querer y poder hacer con lo almacenado, porque esto no dependerá solamente de la cantidad de información que maneje, sino obviamente de su conocimiento de las cualidades y calidad de la misma.

\subsection{Arqueología e información gráfica: dibujos, gráficos e imágenes}

Si hay un dicho aceptado, asumido e incorporado al ámbito de la Arqueología es aquel que reza que "una imagen vale más que mil palabras", y ello se debe a que esa expresión del saber colectivo acumulado supone la solución a varias necesidades planteadas por los restos culturales individualmente considerados y por los yacimientos arqueológicos en sí mismo y cuando han de estudiarse en relación con su entorno, necesidades como:

- el estudio detallado de sus características visibles,

- el estudio de la relación entre éstas y las que no lo son,

- la reconstrucción de lo que se ha conservado incompleto,

- la publicación de los hallazgos y estudios que contribuyen al conocimiento de la Historia.

Desde esta óptica es fácil comprender que la documentación gráfica relacionada con la Arqueología se puede agrupar en dos grandes clases, la "tomada" y la "elaborada", o lo que es lo mismo, por una parte la que el arqueólogo obtiene directamente de la realidad que se encuentra, y por otra la que él mismo fabrica, lo que en los tiempos que corren, cuando la tecnología al uso permite "congelar" la realidad en imágenes impensables hasta hace apenas unos años y además manipulables, es comprensible que lleve a muchos a pre- 
guntarse si sigue siendo necesario que el arqueólogo trabaje no sólo con imágenes, sino también con dibujos que, por muy fieles a la realidad que sean, nunca serán la imagen de la realidad misma.

$Y$ la respuesta es sin duda afirmativa porque el dibujo arqueológico es un dibujo técnico, un dibujo que no por ello ha de rehuir el máximo realismo posible, pero cuya principal finalidad no es reproducir fielmente la realidad visible, sino plasmar gráficamente las características de los restos culturales que el arqueólogo responsable considere necesario en cada caso, es decir, aquellas variables cualitativas y/o cuantitativas que no sólo son signo de identidad del resto en cuestión, sino que además facilitan su estudio sin necesidad de manipularlo a cada momento, su comparación y su publicación.

\subsubsection{Tratamiento y gestión de dibujos y gráficos arqueológicos}

Atendiendo a lo ya señalado en relación con la actividad arqueológica no debe resultar difícil de entender que el arqueólogo ha de enfrentarse en diferentes etapas y facetas de su quehacer científico a la elaboración de diferentes tipos de dibujos (representaciones de objetos, planimetrias, secciones topográficas, estructurales y estratigráficas, representaciones gráficas de datos de diferentes tipos y con distintas finalidades, etc.) que finalmente acaban siendo a su vez diverso tipos de UI que también hacen necesarios su tratamiento y su gestión.

Pero no sólo eso. Cada vez es más evidente que la información arqueológica, en general resulta infinitamente más útil y, sobre todo, más expresiva, si se analiza y estudia debidamente georreferenciada, es decir, si a los datos que expresan los rasgos de los restos del Pasado se suman los correspondientes a su posición en el espacio en el momento de su descubrimiento, en distintas circunstancias y a distintas escalas, como también es obvio que la visualización de construcciones y objetos en tres dimensiones facilita su comprensión y a menudo la interpretación de su significado, amén de la visualización de su forma original tan completa y próxima a la realidad como posible sea su reconstrucción.

La historia del dibujo arqueológico es prácticamente tan antigua como la de la propia Arqueología, pues desde los primeros tiempos de su andadura, incluso cuando ni siquiera gozaba de la consideración de ciencia, estudiosos y aficionados comprendieron la necesidad de materializar imágenes que ellos podían ver pero otros no -porque aún no existía la fotografía, porque excavar suponía alterar lo que se había encontrado ...-, y también de dar a conocer sus descubrimientos y sus personales visiones e interpretaciones de los mismos, si bien es cierto que no siempre con la objetividad que hoy demandan los planteamientos de la ciencia arqueo- lógica y no siempre con la misma calidad artística, ya que las habilidades personales y los medios disponibles no siempre fueron los mismos.

Con el paso del tiempo la Arqueología se fue incorporando a las diferentes corrientes culturales vigentes y en diferentes momentos, según los países, fue adoptando planteamientos metodológicos que la acabaron convirtiendo en lo que es hoy, una ciencia compleja en sus planteamientos, métodos y técnicas de trabajo. Así, de la realización de croquis a mano alzada y sin medidas y de dibujos más o menos artísticos, más o menos realistas y más o menos idealizados, la Arqueología pasó a elaborar dibujos, planimetrías, secciones y reconstrucciones con las características de lo que hoy se considera dibujo técnico, es decir, representaciones de la realidad a las que se incorporan aquellos aspectos de la misma (secciones, proyecciones, reconstrucciones, calidades, etc.) que permiten no sólo su contemplación, sino también su análisis y estudio.

Esos dibujos arqueológicos, que no por técnicos han de estar necesariamente exentos de la máxima calidad estética posible, se pueden clasificar en dos grandes grupos, las representaciones en 2 y 3 dimensiones, respectivamente y cuyo tratamiento y gestión plantean evidentemente distintas necesidades.

\subsection{2. ¿Qué dibuja el arqueólogo?}

Durante muchos años, y gracias a la muy encomiable labor de grandes dibujantes que supieron adaptar sus habilidades artísticas y técnicas a las necesidades de las publicaciones arqueológicas -y vaya desde aquí nuestro sincero reconocimiento a D. Delfín Salas y a $D^{a} M^{a}$ Dolores Fernández-Posse, grandes dibujantes con quienes nos unieron relaciones profesionales pero también de amistad-, los dibujos de materiales arqueológicos o los gráficos que plasmaban diferentes aspectos de la investigación (mapas temáticos, diagramas, etc.) suponian generalmente un proceso que arrancaba de la confección de originales a lápiz y terminaba con el "paso" de éstos a tinta -lo que a su vez obviamente suponía la realización de un segundo original-, requisito indispensable para su publicación habida cuenta además de que la impresión de fotografías ha resultado siempre económicamente más costosa.

Por motivos evidentes, esos dibujos han planteado siempre gran cantidad de problemas, desde el almacenaje de un incontable número de originales a lápiz -sólo hay que pensar en la gran cantidad de piezas de silex o de fragmentos cerámicos que se recuperan en las excavaciones arqueológicas o de monedas y de toda clase de objetos que se guardan en los museos, por sólo citar algunos ejemplos-, cuya calidad se degrada irremediablemente con el tiempo, hasta la necesidad de repetir una y otra vez los originales a tinta en función de las diferentes escalas, composiciones de las figuras y 
cajas de imprenta, rotulaciones, etc. necesarias para las publicaciones correspondientes.

Pues bien, afortunadamente hoy las nuevas tecnologías han puesto en manos de los profesionales de la Arqueología, y evidentemente también en las de los dibujantes y diseñadores gráficos que en su caso trabajen con y/o para ellos, un conjunto de herramientas que solucionan esos problemas y ofrecen otras posibilidades impensables no hace tanto tiempo.

$Y$ es que los programas de diseño asistido por ordenador (COREL DRAW, ALDUS FREEHAND, etc.) permiten elaborar esos dibujos arqueológicos con todas las características técnicas que requieren $y$, si bien es cierto que difícilmente pueden llegar a alcanzar la calidad artística de los que salieron de las manos de los grandes dibujantes, también lo es que presentan otros rasgos no menos apreciables, aunque no siempre comparables.

Pese a que hoy día se pueden obtener imágenes de gran calidad, la Arqueología sigue necesitando dibujos técnicos, aunque no exentos de ciertos cánones estéticos, que no pueden ser sustituidos por fotografías, fotogramas o imágenes digitales, sino que son el perfecto complemento de éstas y de las descripciones de los restos del Pasado, es decir, que constituyen con ellos el conjunto de la información arqueológica.

Durante el desarrollo de diversas fases y facetas de su trabajo, el profesional de la Arqueología realiza planos generales (del área prospectada o excavada, p.e.) y parciales (determinados microespacios o unidades estructurales), cortes y secciones topográficos, secciones estratigráficas y estructurales, topografía de cavidades, dibujos de paramentos, de materiales arqueológicos, etc., es decir, elabora un variado conjunto de representaciones gráficas de diferentes realidades, con diferentes características (escalas, códigos de representación, etc. y con diferentes finalidades, y ello conlleva el inmediato planteamiento de una pregunta - ¿por qué?- de fácil respuesta para quienes nos dedicamos desde hace tiempo a estos menesteres.

Es obvio que determinados restos del Pasado, y por supuesto el propio suelo sobre el que éstos se construyeron, utilizaron, abandonaron, etc. no son "muebles", no pueden trasladarse a un gabinete o laboratorio donde su descripción, análisis y estudio pueda hacerse a partir de su observación directa, y normalmente los restos arqueológicos tampoco son "fracturables" para poder observar p.e. su grosor, o su estado de conservación impide la observación de su técnica de fabricación, su decoración, etc., etc..

Esos y otros datos son "materializables" en el dibujo arqueológico, de tal manera que convierten una representación gráfica de este tipo en una UI -susceptible por tanto de ser considerada, como el propio resto arqueológico, objeto directo de estudio-, de la que "extraer" los datos correspondientes a los atributos de lo representado.
Pero, y visto ahora desde otra óptica, los dibujos arqueológicos pueden ser considerados también como manifestaciones de las UI que facilitan su identificación en ocasiones mejor que las respectivas descripciones textuales, muestran algunos de sus atributos difícilmente aprehensibles por observación directa y complementan la descripción de otros, y que duda cabe de que también es cierto que - y cambiando de nuevo la lente de nuestra óptica - un dibujo arqueológico puede considerarse en su caso como "un dato más" de los que constituyen una UI cuando es uno de los elementos que forman parte de una publicación o de una ficha/registro de una BD, por citar algún ejemplo.

A la vista de todo ello y siempre partiendo de la base de que hoy el dibujo arqueológico es un dibujo técnico que no pretende copiar fielmente la realidad y que en modo alguno puede falsearla ni deformarla, sí se puede concluir sin embargo concluir que puede estandarizarla para:

- uniformizar en lo posible ese tipo de información (información gráfica),

- facilitar la aprehensión de las características de lo representado y la comprensión de las mismas y

- facilitar la publicación y difusión de las características de los restos culturales.

Ese carácter de dibujo técnico convierte al dibujo arqueológico en medio de representación gráfica de aquellos atributos de las UI no visibles, y en consecuencia, no captables por el objetivo de una cámara (p.e. el grosor de las paredes de un recipiente entero, la forma de la sección de la hoja de una espada, la morfología de la empuñadura de un cuchillo que conserve las cachas, etc.) y permite también incorporar observaciones e interpretaciones que resalten y/o expliquen determinados atributos de las UI, e incluso completar carencias cuando lo representado no se halló completo pero su morfología denota que corresponde a tipos formales conocidos, lo que permite su reconstrucción y al "devolver" a lo representado a su realidad original, en la medida de lo posible, hace más fácilmente aprehensible y comprensible la información que lo representado contiene.

Cualquier dibujo arqueológico es por tanto en sí mismo una UI, y como tal, fuente y soporte de datos, lo que convierte a este tipo de representaciones gráficas en uno de los conjuntos de información más amplio, numéricamente hablando, y también más "denso" por el gran volumen de datos que en ocasiones contienen, por todo lo cual a menudo son fuente también, pero de problemas, para el arqueólogo que irremediablemente ha de afrontar su elaboración, archivo, consulta, etc..

\subsubsection{Soluciones "a la carta"}

Pero también para esta faceta de la actividad arqueológica la Informática ofrece soluciones cuya aplicación hoy 
está al alcance de cualquier investigador del Pasado, porque la elaboración, el tratamiento y la gestión de dibujos asistidos por ordenador facilita en gran medida:

- la estandarización y con ello la homogeneización de la información;

- su almacenaje, puesto que no requiere más espacio físico que el necesario para que un ordenador almacene los datos relativos a la posición de los puntos que conforman líneas y/o polígonos, el modo de unión entre ellos y el tipo de relleno si delimitan figuras cerradas, de tal forma que el "peso" del archivo correspondiente a cada dibujo es proporcional al número de puntos que lo conforma, la distancia entre ellos, la extensión de las áreas cerradas y la apariencia de las lineas y superficies generadas;

- su multiplicación, dado que tanto su visualización como su materialización impresa son posibles tantas veces como sea necesario, e incluso su conversión en imágenes, lo que permite obtener tantos "originales" como sea preciso, pero habiendo confeccionado cada dibujo una sola vez;

- su tratamiento, en tanto que la información representada se puede modificar, ampliar, reducir, completar, etc., según las necesidades.

La obtención de dibujos arqueológicos asistidos por ordenador es posible mediante la utilización de programas que "elaboran" imágenes VECTORIALES (COREL DRAW, ALDUS FREEHAND, AutoCAD, etc.), pero llegados a este punto conviene aclarar que el usuario debe diferenciar bien las necesidades para utilizar la herramienta más apropiada en cada caso para cubrirlas, y en este sentido es obvio que el arqueólogo realiza, almacena, utiliza, etc. tres grandes grupos de dibujos: por una parte los de los restos muebles, comúnmente denominados materiales arqueológicos, por otra las planimetrías y secciones de los yacimientos arqueológicos y sus restos inmuebles, y finalmente las reconstrucciones tridimensionales que le permiten recrear la realidad pasada dotando de volumen a los restos inmuebles y, en su caso, incorporando a sus respectivos "ambientes" los materiales arqueológicos relacionados con ellos.

\subsection{4. "Imágenes" e imágenes, figuras en $2 \mathrm{D}$ y en $3 \mathrm{D}$}

Antes de seguir comentando las ventajas del diseño asistido por ordenador para las diferentes variedades de dibujos arqueológicos, parece conveniente recordar, aunque lo haremos también en términos coloquiales, las diferencias existentes entre lo que podemos calificar como "dibujo digital", es decir, IMÁGENES VECTORIALES y lo que normalmente denominamos "imágenes", que son las verdaderas IMÁGENES DIGITALES.
Evidentemente cuando vemos en pantalla la representación gráfica "dibujada" de un objeto, la planta de un edificio, o una estratigrafía, estamos viendo una imagen, pero cuando esa imagen ha sido generada por un programa de diseño gráfico, en realidad estamos visualizando el resultado de la ubicación en un espacio determinado de una serie de puntos relacionados entre si de diferentes maneras, es decir, el resultado de las operaciones realizadas por el ordenador con los datos relativos, como expusimos anteriormente, a la posición de esos puntos en un espacio concreto y a las relaciones existentes entre ellos, o lo que es lo mismo: vemos la "imagen" de un archivo de datos que se sitúan espacialmente no en función de una posición previamente determinada, como en el caso de las verdaderas imágenes digitales a las que nos referiremos más adelante, sino de su relación con otros y con los límites del área en la que han de situarse.

$Y$ esto es algo que es muy importante tener presente cuando se plantea la utilización del diseño asistido por ordenador en Arqueología, porque según el tipo de dibujo que se pretenda realizar será conveniente utilizar un programa $u$ otro, ya que en unos casos la posición espacial de esos puntos es indiferente y en otros no, puesto que, por ejemplo, la representación de un objeto en sí mismo no requiere la de su posición concreta en el espacio pero la de su ubicación en el interior de una sepultura sí, la de la planta de una determinada estructura puede interesar per se e independientemente de su relación con otras o de su ubicación en el yacimiento, pero si se trata de la planta de un asentamiento en la mayoria de los casos interesará no sólo la forma y disposición de sus componentes, sino también su ubicación en relación con una determinada topografía ...

Es más. La tecnología actual permite "convertir" dibujos en imágenes, o lo que es lo mismo, imágenes vectoriales en imágenes digitales, y viceversa, e incluso "manipular" unas y otras con programas específicos de diseño gráfico y de tratamiento de imagen, respectivamente, lo que evidentemente ofrece al arqueólogo una amplia gama de posibilidades a la hora de "jugar" con su variada documentación.

Qué duda cabe que la habilidad personal puede alcanzar un nivel de perfección que no haga necesario el uso previo de lápiz y papel para realizar los dibujos arqueológicos de aquellos restos culturales cuyas dimensiones permiten su manipulación, por lo que no dudamos que en algún caso sea posible que el arqueólogo o el dibujante especializado, utilizando directamente una "tablilla gráfica" como soporte sobre el que dibujar y un "lápiz digital" con el que hacerlo, sea capaz de hacer un dibujo arqueológico del que el ordenador irá almacenando los datos necesarios para permitir su posterior visualización, impresión, etc., pero hemos de confesar que la experiencia indica que no es ese el caso "del común de los mortales".

Decimos esto porque, hoy por hoy, seguimos considerando necesaria la realización de un primer dibujo de los ma- 
teriales arqueológicos "a la manera tradicional", sobre un papel o cartulina y a lápiz, por si hay que corregir, porque es en él donde ha de reflejarse toda la información morfológica directamente observada y porque es mucho más fácil obtener posteriormente, pero a partir de él, esas imágenes vectoriales que veremos como dibujos técnicos en dos dimensiones, técnicamente -y valga la redundancia- mucho más perfectos que cualquier dibujo hecho a mano, homogéneos, fácilmente reproducibles, multiplicables, "multidimensionables", etc.

Ahora bien, también es cierto que ya no hace falta dotar a ese dibujo de calidad artística porque eso lo puede hacer después el ordenador, lo cual supone un importante ahorro de tiempo y de trabajo, y que ese dibujo a lápiz es realmente la base sobre la que obtener los dibujos que nos interesan, pues tras su "conversión" en una imagen digital mediante el uso del escáner, podemos utilizar esa imagen bien para "vectorizar" sus puntos y líneas o bien para "dibujar" -en realidad señalizar la posición de esos puntos en el "área de trabajo" para que el programa los archive- pero sobre ella, es decir, como si hiciésemos un calco en un papel transparente o en un acetato de aquello que dibujamos primero a lápiz, de tal forma que una vez hecho esto podremos añadir o eliminar ciertos elementos, colorear, sombrear y en su caso dotar de ciertas texturas a las superficies que interese, o incluso incorporar la imagen digital de las mismas, rellenar espacios de color o con tramas, añadir rótulos, escalas, o cualquier tipo de indicación necesaria, utilizar esas representaciones gráficas en diferentes tamaños, agrandándolas o empequeñeciéndolas automáticamente cuanto sea necesario y sin detrimento alguno de su calidad ni al visualizarlas ni al imprimirlas, etc., etc.

De lo arriba expuesto se desprende que los programas de diseño asistido por ordenador son una cómoda solución para toda la problemática que rodea al dibujo arqueológico, pero el lector habrá comprobado que al hablar de su aplicación a la representación gráfica de materiales arqueológicos nos referimos solamente al dibujo técnico de los mismos, siempre en dos dimensiones (en adelante 2D), es decir, a dibujos cuyos puntos no está situados espacialmente en un lugar concreto, o no han de estarlo necesariamente, y de los que el ordenador no toma ni archiva su posición real en el espacio, ni "absoluta" -lo que respondería a unas determinadas coordenadas geográficas- ni respecto a los límites de ningún área en concreto, sino que "trabaja" con su posición respecto a los otros puntos que conforman esas figuras.

Puede resultar redundante nuestro hincapié en este aspecto del problema, pero consideramos fundamental su comprensión a la hora de seleccionar las herramientas de trabajo para utilizar la más apropiada en cada caso, porque evidentemente tras este planteamiento se esconden dos realidades que es imprescindible tener en cuenta para optimizar nuestra inversión de tiempo y de trabajo.
Por una parte, y en cuanto a los propios dibujos arqueológicos, es obvio que aquellos que son fundamentalmente descriptivos, es decir, que se confeccionan básicamente para representar las características morfológicas y tecnológicas de los restos arqueológicos, y en su caso los rasgos fundamentales de sus atributos decorativos y/o artísticos, son siempre dibujos "planos", es decir, en 2D, aún cuando en ellos se debe cuidar al máximo la representación de al menos una parte de los mismos, mediante sombreados, para que el observador pueda hacerse una idea lo más concreta posible de cómo es o fue realmente el objeto en cuestión, de tal forma que cuando se recurre a representaciones tridimensionales se prima ésta segunda función del dibujo arqueológico sobre la primera y fundamental: ser una UI cuya observación permita conocer tanto aquellos datos que son visibles en una imagen fotográfica como los que no lo son salvo que se haga un dibujo técnico. De esto se deduce que para elaborar aquellos dibujos que serán UI en sí mismos y cuyos componentes ("puntos") no han de ser relacionados con los de otros, no es necesario utilizar programas preparados para archivar posiciones espaciales reales(coordenadas) ni para relacionar no sólo los puntos que definan figuras en $2 \mathrm{D}$, sino también la tercera dimensión, o dicho de otra forma, que para ese tipo de representaciones gráficas resulta mucho más útil el software elaborado precisamente para eso, para realizar dibujos que, sin dejar de serlo, alcancen altas cotas de realismo, como lo son Corel Draw o Aldus Freehand, por sólo citar algunos de los ejemplos comerciales más conocidos.

Por otra parte, y ahora con respecto al propio software a utilizar, hay que tener en cuenta que todo esto está íntimamente relacionado con la propia filosofía de los programas informáticos, y que por tanto es útil saber que esos que permiten confeccionar dibujos solamente en $2 \mathrm{D}$ almacenan los datos correspondientes a cada uno de ellos por separado, es decir, confeccionando un archivo individual para cada uno, lógicamente porque cada dibujo será una unidad en sí mismo.

Sin embargo, otros programas están "preparados" para almacenar esos datos - repetimos, la posición de cada "punto" componente del dibujo - pero teniendo en cuenta que se va a utilizar también, o que podría hacerse, la posición real de cada uno de ellos en el espacio y no sólo en dos dimensiones, sino en tres -" $x$ " e " $y$ " para 2D, y "z" para 3D-, lo que supone que un determinado dato, una determinada " $x$ ", " $y$ " o "z" puede ser común a varios "dibujos" (los extremos de un muro medianero, la altura de muros de estructuras diferentes, p.e.). Por ello este tipo de programas, como AutoCAD por ejemplo, almacenan los datos en una BD que permite posteriormente visualizar figuras diferentes, según los seleccionados en cada ocasión (una parte de una planta, la planta de un edificio completo, una representación tridimensional de un todo o de una parte y con diferentes perspectivas, etc.), y ante esto es fácil comprender que utilizar este tipo de soft- 
ware para confeccionar simplemente dibujos en 2D que no han de relacionarse con otros, es a nuestro entender infrautilizar una herramienta que, lógicamente, no es fácil aprender a manejar y mucho menos dominar para aprovechar todas sus posibilidades.

Ahora bien, esto no es una defensa a ultranza ni del uso en Arqueología de determinados programas comerciales ni del "abuso" de las representaciones bidimensionales, sino todo lo contrario, un intento de aprovechar al máximo la generosa oferta de la Informática para solucionar problemas no arqueológicos, sino de los arqueólogos y de quienes trabajan directamente con ellos.

De todo lo dicho se deduce que si pensamos que para el dibujo de materiales arqueológicos y para otras representaciones "planas", como por ejemplo las secciones estratigráficas (comúnmente conocidas como "estratigrafías" o "perfiles") o los paramentos (para los que utilizar la fotogrametría a menudo resulta demasiado costoso para el arqueólogo), resultan muy útiles los programas de dibujo en 2D, también pensamos que obviamente para la confección de verdaderas planimetrías -que no son lo mismo que el simple dibujo de una planta-, secciones topográficas y reconstrucciones tridimensionales, lo más apropiado es utilizar un programa que permita "jugar" con las posiciones espaciales reales, georreferenciadas, es decir, con sus verdaderas coordenadas, geográficas o no, según convenga, y obviamente también con la posibilidad de visualizar representaciones en 2D y/o en 3D, máxime cuando hoy la colecta de esos datos puede ser tan rápida, fácil y cómoda como precisas sean las mediciones de un GPS.

\subsubsection{De la fotografía en blanco y negro a la imagen digital}

Si la actualización de la metodología arqueológica ha sido realmente espectacular en la segunda mitad del s. XX se ha debido en buena parte al no menos espectacular avance de las muchas ciencias y técnicas a las que ahora puede recurrir, y en este sentido no cabe duda de la importancia que tiene la fotografía ya en los primeros "pasos" de la actuación de la Arqueología, puesto que supone la posibilidad de captar y capturar información in situ y en el mismo momento de su descubrimiento, y actualmente más aún, ya que no solo es posible almacenar esas imágenes que conservarán para el futuro incluso los datos que, por muchas y diferentes cusas, están abocados a su desaparición una vez que se excavan los yacimientos, sino manipularlas fácilmente hasta "exprimir" su potencial informativo y/o para favorecer y divulgar su conocimiento.

Lejos quedaron ya los tiempos en que el arqueólogo debía acudir al escenario de su trabajo con un complejo y pesado equipo de fotografía en el que no podían faltar varias cámaras, objetivos, carretes, etc. porque debía obtener diferentes tipos de fotografías, en blanco y negro y en color, y en su caso también diapositivas, en función del fin último de cada una de ellas (archivo, publicación, presentación, etc.), y lejos están también los momentos en que, después del trabajo de campo comenzaba una etapa en la que había que decidir cuántas copias había que obtener y con qué características, qué rótulos había que añadir manualmente a esas fotografías, cómo solucionar problemas de publicación de imágenes que se habian tomado en color y había que enviar a imprenta en blanco y negro, y un largo etcétera de complicaciones a las que indefectiblemente se suma la degradación de negativos y copias en papel con el paso del tiempo.

Pero que hoy se pueda obtener documentación fotográfica con otros métodos y técnicas no significa que podamos olvidarnos de la información fotográfica "antigua", porque es parte de esa información necesaria para quien proyecte una actuación arqueológica y/o para quien dirija sus esfuerzos a la investigación, ya que en ambos casos se va a tener que enfrentar a una documentación de características diversas, como lo será indudablemente la que él mismo elabore.

Para el profesional de la Arqueología una imagen no es solamente una "materialización" de una realidad obviamente más objetiva que un dibujo, sino que con frecuencia una imagen puede convertirse en el único testimonio, el único documento de un suceso del Pasado que probablemente no pueda volverse a contemplar a causa de su propia actuación (los yacimientos se excavan, los restos se limpian, algunos se restauran ...), de tal forma que, al margen de su carácter de documento gráfico, para el arqueólogo la imagen es también, según los casos:

- una UI, cuando la considera objeto de análisis y estudio y deduce de ella atributos (datos) relativos a los restos del Pasado que no siempre, y por motivos de muy diversa indole, pueden apreciarse por observación directa;

- un elemento constitutivo de algunas UI - como por ejemplo lo es la imagen de una pieza incluida en una ficha o registro de una BD junto a otros datos (procedencia, localización, descripción, etc.) - que facilitan la identificación de los restos arqueológicos, permiten visualizar algunos de sus atributos e ilustran y/o complementan su descripción y/o la comprensión de otros, y

- un soporte al que incorporar datos que la hacen más útil, resaltando ciertos detalles, añadiendo rótulos e indicaciones, de forma que con frecuencia imágenes "tomadas" (directamente de la realidad o hechas por otros) son el punto de partida para la elaboración de imágenes "generadas" que pasan a incrementar el volumen de información gráfica, tan intimamente ligado a la actividad arqueológica. 
No parece necesario exponer aquí los múltiples problemas que plantea el almacenaje de fotografías, negativos, diapositivas, etc., sobradamente conocido y relativo no sólo a su propio volumen y al de los datos que necesariamente han de acompañarlas (fecha, hora, tipo de cámara y película, etc.) sino también a su accesibilidad y conservación, como tampoco queremos hacer más hincapié en la frecuente necesidad de su multiplicación cuando la edición de los diferentes tipos de trabajos relacionados con la actividad arqueológica (proyectos, informes, memorias, tesis doctorales, publicaciones, etc.) requiere formatos diferentes.

Por ello, en las líneas que siguen nos referiremos directamente a los medios que ahora hay a nuestro alcance para solucionar esos problemas, ya que el arqueólogo de hoy puede utilizar las actuales tecnologías de la imagen digital para trabajar tanto con fotografías y/o diapositivas, digitalizándolas, como con imágenes digitales ya hechas, y evidentemente con las que él mismo genere si las toma ya directamente con cámara digital.

\section{Problemas solucionados}

Tal vez quienes no hayan tenido aún demasiado contacto con el uso de aplicaciones informáticas, se pregunten la razón por la que la imagen digital o IMAGEN RASTER ha supuesto la gran solución para la cuestión, entre otras, del almacenaje de imágenes, hasta el punto de permitir obtener y guardar todas aquellas que se consideren necesarias prácticamente sin límites de cantidad -y sin mayor coste económico sea cual sea su número-, y esa razón es fácilmente comprensible: los ordenadores no almacenan imágenes propiamente dichas, sino los datos necesarios para que esas imágenes puedan ser visualizadas.

Recordaremos ahora, y de nuevo en lenguaje coloquial, que, a diferencia de la imagen vectorial -generada por el ordenador a partir de un archivo de datos relativos a la posición de los puntos que la configuran-, una imagen raster es en realidad el resultado visible de un archivo de datos que, procesados según las "órdenes" contenidas en los programas confeccionados al efecto, "se sitúan" en las "celdillas" (pixeles) de una "rejilla" transformando en colores los códigos correspondientes a cada uno de ellos, de tal manera que el observador visualiza no el dato almacenado, sino el color resultante de la descodificación del mismo y su "aparición" en un determinado lugar de dicha "rejilla".

Esto implica la existencia de una relación directa entre las características de esos archivos y las dimensiones y/o calidad de las imágenes: cuanto mayor sea el número de "celdillas" disponibles para situar los datos de color, mayor será el tamaño de la imagen, pero a igual número de ellas, cuanto menores sean esas celdillas, mayor número de datos por "rejilla" para cada imagen, mayor número de "celdillas" a rellenar de color y por tanto mayor definición o calidad.
Y teniendo en cuenta además que la Informática permite el almacenaje de un gran volumen de datos y diferentes modos de gestión de los mismos, es fácil deducir que la utilización de imágenes digitales soluciona no sólo ese problema de almacenaje, sino también otros de los antes mencionados ya que, una vez guardados los datos correspondientes a una imagen, ésta se puede visualizar -y por supuesto imprimir si es necesario- tantas veces como sea preciso, lo que equivale a decir que es posible "multiplicar" el número de "copias" ilimitadamente, así como, mediante programas cuyo manejo no resulta complicado para el no experto, al menos a nivel básico (PaintBrush, Adobe Photoshop, etc.), es posible también obtener a partir del archivo de datos correspondiente a una misma imagen, copias de ella cuyo tratamiento permite obtener nuevos "originales" con diferentes formatos conseguidos al realizar cambios de tamaño, color, calidad, aspecto, orientación, selección de partes, combinación con otras imágenes, adicción de rótulos, etc.), lo que, indefinitiva, con vierte a la imagen digital en una verdadera "imagen multiuso".

Ahora bien, esas peculiaridades de las imágenes digitales hacen que el arqueólogo que las utilice tenga previamente muy claro qué uso va a hacer de ellas, pues de las características de la imagen obtenida dependen las posibilidades y resultado de su tratamiento e incluso la problemática de su propio almacenaje.

\section{Obtención de imágenes digitales: tamaño, formato, nombre}

Hoy en día la utilización de imágenes digitales en las diferentes facetas de la actividad arqueológica es imprescindible, y a menudo incluso obligada, puesto que permite cubrir todas las necesidades que ella conlleva, desde la documentación del resto arqueológico y su contexto hasta su publicación y/o presentación en ámbitos específicos (conferencias, congresos, simposios) y/o en el desarrollo de tareas docentes, dado que actualmente es práctica común la incorporación de imágenes digitales en la composición de textos de todo tipo de publicaciones y no sólo de las electrónicas.

Por ello el arqueólogo debe plantearse al afrontar su obtención, ya sea directa ya sea porque va a digitalizar dibujos, fotografías en papel, diapositivas, etc., puesto que, y por razones obvias, no requieren las mismas características (color, calidad, tamaño, etc.) imágenes destinadas a su incorporación a una $\mathrm{BD}$, cuyo fin primordial es la rápida identificación del resto arqueológico cuyos atributos se recogen en la correspondiente ficha/registro/UI, para lo que es conveniente que su tamaño sea lo más reducido posible aunque sea en detrimento de su calidad, que aquellas destinadas a su proyección en un aula o sala de conferencias, en cuyo caso es preferible que tengan la máxima calidad posible aunque sean muy "grandes", o bien que las destinadas a su inclusión en 
publicaciones, que deben tener la mejor calidad pero unas dimensiones que se ajusten al espacio que se les destina en las mismas, por citar algunos ejemplos.

Y volviendo a utilizar nuevamente un lenguaje más coloquial que técnico, digamos que las imágenes digitales tiene dos "tipos" de TAMAÑO, el "visible", es decir, al que responden sus dimensiones físicas cuando se visualizan en la pantalla del ordenador o se imprimen y que corresponde al tamaño de la "rejilla" en la que se posicionarán los colores, y el "invisible", es decir el correspondiente al archivo que contiene los datos relativos al tamaño de esa "rejilla", al número de "celdillas" en ha de subdividirse y a los colores que han de posicionarse en éstas y rellenarlas, es decir los datos que determinan su RESOLUCIÓN y cuya cuantificación se denomina, en terminología informática, "peso".

Es fácil comprender por tanto que TAMAÑO y RESOLUCIÓN son caracteres modificables sólo hasta ciertos límites, pues de su directa relación depende la calidad de las imágenes que se obtengan y, por razones obvias, de ésta depende el uso que se pueda hacer de ellas.

Pongamos un ejemplo. Una imagen realizada para su impresión en un tamaño de $10 \times 15 \mathrm{~cm}$, se puede agrandar o reducir en su tamaño visible, pero si ese "estiramiento" o esa reducción son excesivos, inevitablemente perderá calidad visual ya que su resolución de origen (el número de "celdillas" o píxeles" ) habrá de expandirse o constreñirse para adap- tarse a los nuevos límites "físicos", dando como resultado, y tanto en uno como en otro caso, una imagen borrosa, lo que supone un resultado muy diferente al que se obtiene cuando la imagen se observa o se proyecta a través de determinadas lentes, que es lo que en definitiva "hacen" una cámara fotográfica o un escaner.

Pues bien, la tecnología actual ha desarrollado diferentes variedades de "estructuras" para los archivos de las imágenes raster, que responden a distintas modalidades de los parámetros necesarios para la visualización de sus componentes (grado de compresión, canales de color, etc.), lo que determina sus posibilidades de tratamiento según el caso y a lo que responde la extensión que acompaña al nombre de los respectivos archivos, es decir, su FORMATO, que puede ser, citando aquí y ahora sólo los más comunes, uno de los recogidos en la Tabla 3.

Y por último, algunas indicaciones sobre algo que nada tiene que ver con el tamaño, la definición ni el formato de las imágenes digitales pero sí con su utilización, como es el nombre que se asigne a sus correspondientes archivos, un detalle que si el arqueólogo planifica lógica y metódicamente, posteriormente le facilitará su almacenaje, tratamiento y gestión. En este sentido consideramos ciertamente recomendable tener presentes las peculiaridades de las imágenes digitales y sus múltiples utilidades a la hora de asignar nombre a esos archivos, ya que:

Tabla 3

\begin{tabular}{|c|c|c|c|c|c|}
\hline $\begin{array}{l}\text { Tipo de archivo } \\
\text { (extensión) }\end{array}$ & Tipos de imagen & Color & Resolución & Compresión & Otras características \\
\hline BMP (Bit Map) & $\begin{array}{c}\text { Mapa de bits } \\
\text { (datos presentes/ } \\
\text { ausentes) }\end{array}$ & Ajustable & Ajustable & Escasa & $\begin{array}{l}\text { Estándar de } \\
\text { Windows }\end{array}$ \\
\hline $\begin{array}{l}\text { GIF (Graphics } \\
\text { Interchange } \\
\text { Format) }\end{array}$ & Mapa de bits & Indexado (56 máx.) & $\begin{array}{l}\text { Estándar: } 72 \text { DPI } \\
\text { (dots per inch o } \\
\text { puntos por pulgada) }\end{array}$ & Hasta 25\% & \\
\hline $\begin{array}{l}\text { JPEG (Joint } \\
\text { Photographic } \\
\text { Experts Group) }\end{array}$ & Mapa de bits & $\begin{array}{c}\text { Verdadero } \\
\text { (hasta 16.777) }\end{array}$ & Estándar (72 DPI) & $\begin{array}{c}\text { Alta (con pérdida } \\
\text { de hasta } \\
1 / 20 \text { y más) }\end{array}$ & \\
\hline $\begin{array}{l}\text { PCX (Picture } \\
\text { eXchange) }\end{array}$ & & $\begin{array}{l}\text { Indexado o } \\
\text { a } 24 \text { bits }\end{array}$ & & Sin pérdidas & \\
\hline $\begin{array}{l}\text { PNG (Portable } \\
\text { Network } \\
\text { Graphics) }\end{array}$ & $\begin{array}{l}\text { Mapa de bits } \\
\text { (no sujetos } \\
\text { a patentes) }\end{array}$ & $\begin{array}{c}\text { Indexado (256 máx.) } \\
\text { o verdadero } \\
\text { (hata 16.777) }\end{array}$ & Ajustable & Con filtro previo & $\begin{array}{l}\text { Posibilidad de } \\
\text { transparencia }\end{array}$ \\
\hline $\begin{array}{l}\text { PSD (PhotoShop } \\
\text { Document) }\end{array}$ & Mapa de bits & Ajustable & Ajustable & Baja & Con capas \\
\hline $\begin{array}{l}\text { TIFF (Tagged } \\
\text { Image File } \\
\text { Format) }\end{array}$ & Mapa de bits & Ajustable & Ajustsable & Alta & \\
\hline $\begin{array}{l}\text { WMF (Windows } \\
\text { Metafile) }\end{array}$ & Vectorial & Ajustable & Ajustable & & \\
\hline
\end{tabular}


- dado que se puede hacer de ellas un número ilimitado de copias y que cada una de éstas puede almacenarse en diferentes "contenedores" (archivo fotográfico, BD, textos, hipertextos, presentaciones, etc.), consideramos más útil mantener el mismo nombre de archivo siempre que no se hayan hecho modificaciones ("imagen 01" p.e.), y sin embargo añadir al mismo alguna indicación bien del tratamiento que se ha dado a la imagen en cuestión ("imagen 01 BN": copia de "imagen 01" convertida en imagen en blanco y negro / escala de grises, "imagen 01 reducida", "imagen 01 detalle $x "$ p.e.) si esos "contenedores" no van a llevar las imágenes incorporadas, sino que "buscarán" la imagen correspondiente cuando sea necesario visualizarla;

- por otra parte, y puesto que el tratamiento de imágenes digitales permite realizar en ellas multitud de modificaciones, creemos muy recomendable, en primer lugar efectuar esas modificaciones siempre sobre copias de la imagen original, para evitar accidentes que impidan volver a tener el archivo original intacto, $y$ por otra parte cuando el programa solicite un nombre para el archivo de la copia modificada, añadir al nombre original alguna indicación de la modificación hecha sobre esa copia (p.e. "imagen 01 fecha", "imagen 01 enfocada", "imagen 01 ajuste color", etc.

Finalmente, y obviamente conscientes de que cada arqueólogo tiene sus preferencias y criterios personales para la sistematización de la documentación que maneja pero en función de la propia experiencia, siempre buena consejera, sugeriremos dos últimas ideas de comprobada eficacia: la conveniencia de asignar a las imágenes digitales nombres que permitan la rápida identificación de su correspondencia a yacimientos, áreas de trabajo, restos arqueológicos, etc., sin necesidad de proceder a su visualización ("habitación N", "contexto X", "fragmento xxxx", etc.) y la necesaria inclusión de tantos ceros a la izquierda de los numerales como sea preciso, o de lo contrario cuando intentemos seleccionar una imagen en una lista ordenada, la "imagen 2" no aparecerá después de la "imagen 1", sino de la "imagen 1999", por poner un ejemplo que suponemos suficientemente ilustrativo.

\subsection{Información arqueológica y espacio: los Sistemas de Información Geoarqueológica (SIGA)}

Indudablemente los avances de la metodología arqueológica no son fruto solamente de la aplicación de las novedades que otras ciencias y técnicas van ofertando, y cada vez más rápidamente, sino más bien consecuencia de las corrientes culturales que en cada momento histórico marcan los cambios de los planteamientos básicos de la propia Arqueología, cambios que en unos casos llevaron al rechazo de determinados métodos de trabajo, y prueba de ello ha sido la llamada Arqueología "postmoderna", y en otros al extremo contrario, a intentar aprovechar en pro de una Arqueología cada vez más científica, toda novedad que pueda suponer una mejora en el método de nuestra Ciencia y, consecuentemente, en los resultados de su puesta en práctica.

Los profesionales de la Arqueología, una ciencia de la Historia cuyos restos se han conservado en la Tierra, cuyas expectativas les llevaban a sentirse más atraídos por la corriente que fluye en esta última dirección, se acercaron muy pronto a una herramienta informática que, en cuanto el software comercial lo hizo posible, se convirtió en casi imprescindible tanto para las actividades arqueológicas de gestión como de investigación, aunque no siempre de fácil utilización: el denominado SIG (Sistema de Información Geográfica) o GIS (Geographical Information System).

A fin de facilitar la comprensión del "mundo de los SIG" por quienes al leer estas líneas no tengan ya un sólido conocimiento del mismo, recurriremos de nuevo al lenguaje coloquial para exponer que se trata de conjuntos de programas -en realidad debería hablarse de "sistemas", en plural, porque hay más de uno- cuyo fin último es la topología (etimológicamente "estudio del suelo" y por tanto de sus características y de todo lo relacionado con él), que trabajan con información geográfica "elaborando" representaciones gráficas del terreno más o menos próximas a la realidad con datos relativos a diferentes variables de éste que definen su morfología, "poniendo" en relación con ellas información temática, geográfica o no, y permitiendo la visualización también de esas relaciones.

Consecuentemente, es fácil comprender que para que el "sistema" funcione es precisa la concurrencia de sus dos tipos de componentes básicos:

- una INFORMACIÓN constituida por datos espaciales y datos temáticos, y

- un SOFTWARE conformado por programas que generen $\mathrm{BD}$ o permitan la incorporación de información desde BD externas, programas de gestión de BD, $\underline{\text { SIG }}$ propiamente dichos, programas para la actualización de datos y relaciones y programas para la recuperación de la información capturada y gestionada.

Hasta hace bien poco tiempo, y aún hoy sigue haciéndolo, el arqueólogo recurría con mucha frecuencia a los mapas temáticos para representar gráficamente la relación existente entre uno o varios elementos geográficos, y a menudo también administrativos (límites políticos, orografía, hidrografía, recursos naturales, etc.) y elementos arqueológicos de diferente carácter (yacimientos en general, determinados tipos de restos culturales en particular, etc.), elaborando así unas representaciones en las que sobre una base constituida por ciertos rasgos del suelo, o todos, aparecían datos no 
pertenecientes al suelo pero relacionados con él en tanto que sobre él se hallaron, y esos mapas temáticos se utilizaban tanto para interpretar la situación visualizada como para ilustrar esa situación, enfatizando, remarcando, utilizando diferentes escalas, etc. los datos sobre los que se quería Ilamar la atención del observador.

Pues bien, el método de funcionamiento de un SIG es básicamente muy semejante al utilizado por el arqueólogo en el caso de los mapas temáticos, ya que en definitiva persigue también la identificación, representación, análisis y estudio de las relaciones existentes entre datos geográficos y datos temáticos, pero en la práctica hay una diferencia fundamental de partida: el arqueólogo tenía que conseguir el mapa-base, o en su caso confeccionarlo, reunir la información no geográfica y situarla sobre él, mientras que el SIG sólo necesita contar con los datos relativos a uno y otra para permitir la visualización de ambos tipos de datos y de la relación existente entre ellos.

\subsection{1. ¿Cómo desarrolla su "actividad" un SIG?}

No resulta demasiado complicado entender qué "hace" un sistema de información geográfica, y así se explica que en los últimos años se hayan llevado a cabo numerosas aplicaciones de los mismos en el campo de la Arqueología, pero pensamos que antes de decidir cual va a utilizar, cuándo y con qué fin, el arqueólogo debe tener a menos una idea básica de cómo funcionan realmente estos sistemas de gestión de la información, puesto que su tarea no acabará en la representación visible de ciertos datos, sino que habrá de interpretar lo que vea y, en su caso, incluso podrá utilizar el propio sistema para enfatizar, remarcar, etc. aquellas situaciones en que se base su interpretación.

\section{Obtención de la Información}

Como ya se ha señalado, el SIG utiliza como fuentes de información Bases de Datos, una sola o tantas como temas se vayan a relacionar con la información geográfica, pero en este caso, la condición que ha de cumplirse para que el sistema funcione es que esas $\mathrm{BD}$, de temática diferente, estén interrelacionadas porque contengan algunos datos comunes, IDENTIFICADORES, aunque por razones obvias, otros no lo sean.

Pongamos un ejemplo: Si vamos a utilizar un SIG para buscar, representar e interpretar la posible relación existente entre los datos A: "forma del relieve" y B: "cursos de agua" de un área geográfica comprendida en determinadas coordenadas (datos geográficos), y los datos $1:$ "con fortificaciones", 2: "de la Edad del Bronce", 3: "con cazuelas" y 4: "con cerámicas lisas" (datos temáticos), lo normal es que esos datos estén en diferentes BD, a las que denominaremos Geografía, Yacimientos, Asentamientos, Materiales arqueológi- cos y Cerámicas, que contengan información sobre topografía e hidrografía, yacimientos arqueológicos, tipos de asentamientos prehistóricos y materiales arqueológicos de la Prehistoria Reciente, respectivamente.

Pues bien, para que el SIG pueda "trabajar" y relacionar los datos correctamente, es necesario que la BD Geografía tenga datos comunes con la BD Yacimientos, p.e. las coordenadas geográficas correspondientes a los yacimientos arqueológicos localizados que en ambos casos deben estar "posicionadas" en "campos" con la misma denominación, -p.e. "Coordenada X", "Coordenada Y" y "Coordenada Z"-, para que el sistema pueda "situar" los yacimientos arqueológicos cuando identifique los mismos "continentes"/"campos" con los mismos "contenidos"/datos, y asi sucesivamente, de tal forma que el resultado final sea la representación visible de la localización geográfica de los yacimientos arqueológicos con los atributos "2", "1", "4" y "3", -para lo cual se han "extraído" los correspondientes datos de las BD Yacimientos, Asentamientos, Cerámicas y materiales arqueológicos, respectivamente, -en un mapa en el que se visualicen los atributos "A" y "B"del suelo "tomados" de la BD Geografía, o lo que es lo mismo, en un mapa temático en el que aparezca representada la posición espacial real de los asentamientos fortificados de la Edad del Bronce localizados en un área geográfica determinada y en los que se ha detectado la presencia de cazuelas de cerámica lisa ...

Queda claro pues que trabajar con un SIG supone hacerlo con DATOS GEOGRÁFICOS Y TEMÁTICOS, ya sean estos CUALITATIVOS O CUANTITATIVOS, y afortunadamente, la ENTRADA DE DATOS es sumamente versátil, lo que permite que su campo de aplicación sea inmensamente amplio al permitir que los datos entren a formar parte del sistema por digitalización directa (teclado, tablilla gráfica), como archivos de texto, como BD confeccionadas ex profeso o resultado de otras aplicaciones (dBase, Excel, CAD), como imágenes (desde scanner, Word File, etc.), como datos emitidos por sensores remotos (satélites) e incluso como datos enviados desde terminales interactivas (estación total, GPS).

Y para gestionar posteriormente esa información obtenida de diferentes fuentes y/o por diferentes métodos y puesto que realmente son dos tipos de "operaciones" las que debe poder realizar para cumplir su cometido, "trabajar" con los datos y permitir la visualización de la información georreferenciada, el SIG utiliza a su vez dos tipos de sistemas: Ios SISTEMAS DE GESTIÓN, conocidos como SGBD (Sistemas Gestores de Bases de Datos) o como DBMS (Data Base Management System), diferenciados por sus distintos lenguajes de programación, ya sean de descripción (lenguaje DDL) o de consulta (lenguaje SOL), y también los SISTEMAS DE GENERACIÓN DE MODELOS de visualización, que pueden ser vectoriales, raster o "modelos orientados a objetos" y a cuya utilidad en el campo de la Arqueología nos referiremos más adelante. 
Sistematización, gestión, utilización y salida de la información

Una vez obtenida esa heterogénea información con la que el SIG "trabajará" en la medida que permitan sus propios componentes, los pasos siguientes en su "actividad" son lógicamente la SISTEMATIZACIÓN DE LA INFORMACIÓN, objetivo que alcanza elaborando sus propias $B D$, y una compleja GESTIÓN DE LA INFORMACIÓN, "pasos" que cumplen una serie de funciones, cuyo enunciado acompañaremos de algunos ejemplos para facilitar su comprensión, como:

- Funciones de edición y actualización: detección automática de errores, verificación, edición, sustitución o modificación de datos, edición o modificación de "estructuras de datos" (posteriormente visualizables como puntos, líneas, polígonos, píxeles);

- Funciones analíticas:

- Conversión de límites difusos (datos con valores muy distantes) en límites precisos (ajuste valores "intermedios") -lo que permite la conversión de modelos raster en modelos vectoriales-; p.e. determinación de la extensión de un yacimiento arqueológico a partir del área de dispersión superficial de sus restos.

- Ordenación de atributos en función de valores especificados (p.e. ordenación de un conjunto de yacimientos arqueológicos en función de su grado de investigación).

- Búsqueda de polígonos en base a atributos especificados (p.e. búsqueda en una ciudad romana de viviendas con pinturas murales).

- Detección de bordes (p.e. búsqueda del límite del área de dispersión de arpones aziliense).

- Cálculo de distancias (p.e. cálculo de la distancia media entre tumbas megalíticas y los correspondientes asentamientos).

- Resumen de datos temáticos por polígono/píxel (p.e. resumen de recurso explotables $/ \mathrm{Km}^{2}$ en un determinado territorio).

- Cálculos estadísticos para contenidos de polígonos o áreas circulares marcadas interactivamente (p.e. porcentaje de restos arqueológicos relacionados con la siega en un radio de $5 \mathrm{Km}$ alrededor de un asentamiento).

- Búsqueda del "vecino más próximo ".

- Análisis de proximidad (p.e. localización de yacimientos de minerales de plomo en un área de 25 $\mathrm{Km}^{2}$ y cálculo de distancias a los mismos desde el puente romano de ...).

- Búsqueda de puntos en un polígono (p.e. localización en la zona $A$ del territorio $B$ de cuevas con representaciones de bisontes).
- Cálculo de pendientes a partir de la coordenada "z".

- Cálculo de longitud de pendientes.

- Definición de límites de divisorias de aguas a partir de datos topográficos.

- Cálculo del área de un polígono o de un grupo de polígonos (p.e. cálculo del área ocupada por el barrio $C$ en la ciudad $B$, o de la manzana $L$ a partir de las áreas ocupadas por sus viviendas y calles).

- Asignación de "pesos selectivos" a distintos atributos para generar y visualizar un modelo de su importancia relativa, es decir en relación unos con otros (p.e. localización de recintos amurallados que coincidan en alguno/s de su/s tramo/s con el límite provincial de ...).

- Localización de polígonos contiguos.

- Generación de contornos mediante técnicas de interpolación (p.e. diseño de la planta de un recinto de fortificación excavado sólo parcialmente)

- Otras.

- Funciones de combinación de diferentes "capas" de información":

- Adicción de una o más "capas" de información a la capa-base (p.e. "superposición" de la capa "dólmenes" a la capa "vías naturales de comunicación").

- Eliminación de elementos de una "capa" seleccionados en el conjunto de elementos de otra (p.e., eliminación de los "no excavados", correspondientes a la capa "estado de investigación", de la capa "yacimientos musterienses ").

- Intersección o multiplicación de varias "capas" para crear otra (p.e. intersección de las capas "municipios prospectados" y "yacimientos romanos" para crear la capa "yacimientos romanos afectados por las obras públicas que comenzaron en 2007).

No es difícil comprender que ese cúmulo de "operaciones" realizadas sobre los datos en definitiva, y en términos coloquiales, no supone sino preparar la información para su posterior utilización, permitiendo así su ANÁLISIS y el PLANTEAMIENTO DE HIPÓTESIS, la VERIFICACIÓN de éstas y la realización de los AJUSTES necesarios para la ELABORACIÓN DE MODELOS TEÓRICOS que también deber ser sometidos a una VERIFICACIÓN y a los correspondientes AJUSTES precisos para entonces proceder a confeccionar la REPRESENTACIÓN DEL MUNDO REAL O DE UNA PARTE DEL MISMO (el espacio seleccionado) prevista, en 2D o en 3D con la que poder CONTRASTAR LAS HIPÓTESIS (de partida) -MODELOS teóricos previamente elaborados, para, tras proceder de nuevo a la realización de los AJUSTES necesarios, permitir finalmente la VISUALIZACIÓN:

* de REPRESENTACIONES DEL MUNDO REAL O DE UNA PARTE DEL MISMO, si se ha seleccionado un espacio 
determinado, en las que los datos geográficos tengan la apariencia más próxima a la realidad posible, y en su caso los datos temáticos también, o bien

* de MODELOS PREDICTIVOS, cuya apariencia no responde a la realidad pero permite, ante la detección de determinadas "situaciones" y/o "panoramas", predecir otros no representables aún porque no se dispone de la información suficiente, o bien

* de MODELOS ENFATIZADOS, es decir, representaciones de la información en las que se resaltan determinados datos para llamar la atención del observador sobre ellos y/o sobre la ausencia de otros, con lo que en ocasiones esa información pierde cualquier parecido con el mundo real, porque no es eso lo que se pretende, pero gana en expresividad, puesto que puede facilitar enormemente la interpretación de la situación representada.

Obviamente la última etapa de la "actividad" del SIG se plasma en la SALIDA DE LA INFORMACIÓN, ya sea por pantalla, impresora, ploter, etc.

Pero llegados a este punto, tal vez el lector se sienta algo abrumado por esta sintética descripción de lo que es un SIG y se esté ya planteando que, sin dudar de la utilidad de este tipo de herramientas, no parece fácilmente comprensible sin embargo la que puedan tener para una ciencia como la Arqueología en la que se trabaja con datos geográficos y temáticos pero en la que a priori parece imposible poder llegar a contrastar hipótesis relativas al Pasado o confeccionar modelos que representes situaciones pretéritas cuando somos conscientes de que no conocemos la totalidad de los datos, lo que permitiría comprobar la veracidad de los mismos ...

\subsubsection{Arqueología y Sistemas de Información Geográfica: del SIG al SIGA y al SIAE}

Es cierto que el "mundo" de los sistemas de información geográfica puede parece especialmente lejano y hasta casi inalcanzable para el arqueólogo que pretenda sencillamente utilizarlos, pero, sin intentar en modo alguno minimizar su complejidad, sí es posible afirmar sin embargo que realmente no es así, sobre todo si ese profesional de la Arqueología antes de convertirse en usuario intenta conocerlos y comprenderlos lo mejor que le sea posible.

En definitiva, los SIG "fabrican" representaciones gráficas de "estructuras" compuestas por datos del mundo real -sean éstos geográficos, en el más estricto sentido del término, o no, es decir, o sean temáticos- relacionados entre sí en mayor o menor medida, ubicándolos a su vez según su posición espacial "absoluta", respecto a la propia Tierra, o bien relacionándolos con un espacio predeterminado al que podemos considerar como el área "de trabajo" en cada caso.
Tanto los datos geográficos como los temáticos pertenecen a la realidad en tanto que existen, o pueden existir en la mente humana (hipótesis), pero evidentemente no toda esa realidad se puede "fotografiar" para poderla ver, bien porque no se conocen todos los datos (p.e. todos los yacimientos de carácter funerario de una determinada región), porque no todos son visibles con una sola mirada del ojo humano (p.e. la ubicación de todos los yacimientos arqueológicos que se hallen en un determinado territorio), porque son datos parciales de lo que fue realidad en el Pasado (p.e. los verdaderos límites de las áreas ocupadas por los primeros hombres) o porque algunos aún son sólo un "futurible" (los yacimientos arqueológicos existentes en un territorio no prospectado, por citar algún ejemplo).

Pero hay que tener bien presente que un SIG no elabora "copias" de la realidad, sino modelos que, a partir de la información seleccionada, gestionada de diferentes formas, representan y permiten visualizar "la realidad que se les pide", y éste es quizá el aspecto que más puede interesar al arqueólogo, ya que, a fin de cuentas, él será quien seleccione la información y el SIG será "quien" trabaje con ella, él será quien "pedirá" visualizar determinadas realidades y el SIG será lo que le permitirá hacerlo pero, finalmente, será el arqueólogo quien habrá de interpretar la realidad que visualice para reconstruir la Historia que dio lugar a la misma, a menos que utilice el SIG únicamente como herramienta de representación gráfica.

Por todo ello cabe ahora prestar especial atención a algunos aspectos relacionado con esos modelos que pueden ser generados por un SIG, porque de sus peculiaridades y modo de permitir la visualización de la información depende la conveniencia de utilizar unos u otros, según el cada caso.

\section{Los modelos vectoriales}

Son representaciones que permiten visualizar la información a base de puntos, líneas o polígonos, en las que:

* los puntos corresponden a la localización georreferenciada de "unidades de información" constituidas por 1 o varios datos; ejemplos de ello serían las visualizaciones en los límites de la pantalla (correspondientes a determinadas coordenadas geográficas) de los puntos correspondientes p.e. a los yacimientos de época medieval (único dato: "clasificación cronocultural") localizados en un determinado municipio o a yacimientos de época medieval, prospectados y con cerámica califal (datos "clasificación cronocultural" + "grado de investigación" + "tipo de cerámica"), respectivamente;

* las líneas o cadenas unen puntos correspondientes a "unidades de información" semejantes pero no iguales, 
es decir, con algunos datos comunes, pero no todos, permitiendo así visualizar p.e. las líneas correspondientes a la red fluvial existente en un determinado territorio al unir entre sí los puntos correspondientes a su vez a la ubicación espacial de los lugares por los que discurren los distintos ríos, ríos cuyos datos constituyen diferentes "unidades de información" conformadas por datos que pueden ser incluso iguales en algún caso ("x"/"y"/"z"/"navegable"/"no navegable") pero nunca serán exactamente los mismos;

* los polígonos delimitan áreas cerradas -definidas por líneas que unen puntos- en las que se encuentran "unidades de información" con datos coincidentes, como lo sería el polígono que permita visualizar el límite de un determinado municipio al unir la línea determinada por los puntos que representen la posición espacial de los lugares donde se ha fijado ese límite, o el que permita visualizar el límite del área ocupada por los municipios en los que haya yacimientos arqueológicos y también de minerales metálicos.

Evidentemente estos modelos vectoriales requieren contar en su BD con unos datos geográficos entre los que figuren como mínimo 2 coordenadas ( $x$. y) por punto si van a generar imágenes vectoriales en $2 \mathrm{D}$, y una tercera $(\mathrm{z})$ si esas imágenes han de ser en $3 \mathrm{D}$, y resultan especialmente útiles para visualizar las relaciones existentes entre "objetos geográficos", es decir, "unidades de información" georreferenciadas.

\section{Los modelos raster}

No obstante, si los límites de las "unidades de información" a relacionar con los datos geográficos son difusos -por no bien conocidos-, es decir, no responden a coordenadas geográficas concretas, como sería el caso, p.e., del área de actividad comercial de diferentes asentamientos de un mismo grupo cultural ocupante de un determinado territorio, un SIG puede "fabricar" otro tipo de modelos, partiendo directamente de la BD o "reconvirtiendo" modelos vectoriales y generando para su visualización imágenes raster en $2 \mathrm{D}$ o en $3 D$, en los que, a diferencia de los modelos vectoriales, no "prima" la ubicación espacial de los datos sino la proximidad de sus valores en relación con ésta.

Esas imágenes serán también la representación visible de la información seleccionada, por una parte la geográfica correspondiente a ese territorio (topografía, hidrografía, vegetación, etc.) y por otra la representativa de esa actividad comercial (temática), p.e. la relativa a los lugares donde se han hallado producciones de ese grupo cultural, serán imágenes que responden a retículas o mallas regulares de "celdillas" (píxeles) para cuyo "diseño" el SIG, que ha atribuido a cada píxel un valor numérico que representa su valor temá- tico, sea éste cualitativo ("cerámica decorada", "orfebrería", "colgantes de hueso") o cuantitativo ("3", "5", "46", etc. objetos exportados), divide el espacio seleccionado o "área de trabajo" (área geográfica a estudiar) en un número de píxeles proporcional a la cantidad de valores incluidos en él - lo que obviamente supone que a mayor número de datos, mayor número de píxeles, y por tanto retícula con celdillas más pequeñas, pero más tupida, y como resultado, imagen de mayor resolución -y sitúa los datos temáticos en los píxeles en función de la relación de proximidad existente entre su posición espacial y su valor numérico.

En resumen, la imagen que permite, en el caso del ejemplo citado, la visualización de la/s relación/es entre las características del escenario (el medio geográfico) en el que se desarrollaron y las de las actividades comerciales de aquel grupo cultural, deducidas de la presencia en ese espacio de diferentes tipos de materiales arqueológicos y/o del número de objetos fabricados y comercializados por dicho grupo, (la información temática), es en realidad un modelo en el que los datos temáticos se verán representados como píxeles con uno u otro color en función de su posición espacial (más o menos alejados de los centros de producción, en las proximidades de vías de comunicación, etc.) y de sus características (tipos de objetos/número de hallazgos), y por tanto una imagen que representa no el mundo real, no una fotografía del territorio y los hallazgos, en la que obviamente las diferencias de tamaños sólo permitirían ver o el primero o alguno de los segundos, pero nunca ambos a la vez, sino un conjunto de "acumulaciones" de color, representadas en 2 ó en 3 dimensiones, cuyas extensión, densidad, distancia, etc. hacen visibles unas situaciones que el arqueólogo habrá de interpretar.

\section{Los "modelos orientados a objetos"}

Menos utilizado hasta ahora, pero muy útil en el ámbito de la problemática arqueológica es otro tipo de modelos que puede generar un SIG denominados "modelos orientados a objetos" por su adaptación a una variedad muy especial de "objetos geográficos", entendiendo por tales, como ya señalamos, de "unidades de información" georreferenciadas, concretamente aquellos que tienen uno o varios atributos de valor variable, situación a la que responden muchos conjuntos de información arqueológica, ya que ésta es per se cambiante en función de los datos que aportan los nuevos descubrimientos, la aplicación de técnicas analíticas $y$, evidentemente, el desarrollo y avance de la investigación histórica.

Para generar estos modelos, el SIG "trabaja" sobre BD con datos "dinámicos", es decir, con valores cambiantes -como lo serían p.e. los datos "cronología absoluta" y "clasificación cronocultural" en muchos casos de la Arqueología, especialmente de la pre y protohistórica, ya que nuevos 
descubrimientos, avances tecnológicos y revisiones a menudo modifican los valores del primero, quizá en un solo "objeto"/yacimiento, pero con frecuencia una modificación como esa conlleva la de los valores del segundo en varios-, y sometiendo la información a diferentes procesos en función de las variaciones de esos datos dinámicos, generan agrupaciones o "clases de objetos geográficos", lo que "traducido" al ejemplo citado, supondría la agrupación automática de la información relativa a yacimientos contemporáneos (p.e. "del V milenio", "de la primera mitad del I milenio AC", etc.).

Es más, en estos casos el SIG no sólo agrupa en "clases" sino que también identifica procesos en los cambios de los datos dinámicos - p.e. en la clase "yacimientos del II milenio AC" identificaría el proceso de cambios producido al sustituir las dataciones obtenidas por $\mathrm{C} 14$ sin calibrar por las resultantes de su calibración y por el que varios de sus componentes pasarian a formar parte de otra clase diferente-, y por ello las propias "clases" pasan a ser también "clases dinámicas", de tal forma que, "trabajando con las variaciones conocidas, el propio SIG puede generar también modelos predictivos cuya visualización, como se ha apuntado, es posible mediante la generación de imágenes bien vectoriales, bien raster.

Esperamos que las líneas precedentes hayan servido para una mejor comprensión de las múltiples posibilidades que los sistemas de información geográfica ofrecen a muchas facetas de la labor arqueológica, desde la propia elaboración de proyectos de intervención y de investigación hasta el estudio de los resultados obtenidos.

No es que la Arqueología sea una Ciencia "de la Tierra", pero sí que su objeto de estudio, los restos arqueológicos, son elementos del mundo real que, como la Historia, siempre están relacionados con el espacio y se encuentran en la propia Tierra, en su superficie o bajo ésta, en el mismo lugar en que el Hombre los depositó o abandonó y tal y como lo hizo, o desplazados, cubiertos, modificados, etc. por los procesos postdeposicionales en los que tanto el Tiempo y el Hombre como la propia Tierra han sido y son los principales actores.

Así mismo hoy es evidente que la información arqueológica plantea una serie de problemas para los que un SIG puede resultar el mejor medio de solución. Es una información de origen diverso (los yacimientos arqueológicos, la información recogida y generada en "el campo", el laboratorio, el gabinete, necesariamente ligada a la que proporciona el paisaje; el conjunto de datos que la conforman es incompleto, porque no conocemos todos los restos de la vida del Hombre sobre el Planeta ni sabemos todo de ellos; se observa una clara diversidad de criterios entre los profesionales de la Arqueología; es preciso sistematizar toda esa información, diversa y heterogénea y valorarlas antes de seleccionar las unidades de información" o conjuntos de datos con los que trabajar ...
Creemos que por tanto es evidente también la íntima relación que debe haber entre la Arqueología moderna y esa herramienta informática, hasta el punto de que pensamos que de su aplicación se deriva, o se derivará en un futuro esperemos que muy próximo, un buen número de verdaderos Sistemas de Información Geoarqueológica, por lo que no parece excesivo proponer que en adelante las siglas que identifiquen habitualmente a esos Sistemas de Información Geográfica y Arqueológica sean directamente SIGA, es decir, sistemas que pueden permitir resolver muchos tipos de problemas arqueológicos pero especialmente aptos para su utilización cuando la actuación de la Arqueología es a nivel "macroespacio" o territorio, y SIAE (Sistemas de Información Arqueológica Espacial) cuando esa actuación se desarrolla en los límites de un "mesoespacio", un yacimiento arqueológico, o incluso de un "microespacio", pues bien podemos calificar así al ocupado por el o las áreas excavadas de un yacimiento o por una o varias unidades estructurales del mismo, pues en estos casos puede no ser necesario referenciar esa información a coordenadas geográficas, sino a las convencionalmente asignadas a las áreas de trabajo.

De cualquier forma, SIGA y SIAE serán sistemas de gestión de la información arqueológica que permitirán, al relacionar datos espaciales y temáticos, resolver algunos problemas, plantear nuevas hipótesis y generar nuevos modelos y también verificar las primeras y perfeccionar los segundos, pero, como ya señalamos en otro lugar, el verdadero problema que late detrás de todo eso es que si el arqueólogo no conoce bien la información, mal sabrá qué "preguntas" debe hacer por muy bien relacionada que tenga esa información con el espacio, mal podrá saber cuántas y cuáles serán las "respuestas" que los programas informáticos le permitan visualizar, o si son incompatibles o excluyentes entre sí ...

\subsection{La Inteligencia Artificial, un gran reto para la Arqueología}

Tal como hemos planteado las cosas hasta este punto, podría parecer que la información arqueológica sigue siendo un problema, pero un problema para el que ahora la Informática nos ofrece una amplia gama de soluciones, y que el reto a que aludimos en el título de este artículo viene "lanzado" desde esa información hacia el arqueólogo y del que éste, recurriendo a las nuevas tecnologías, puede salir airoso, pero a nuestro modo de ver, la situación actual no solo no es tan "simple", sino que además en este caso esa ciencia aún considerada por muchos más "auxiliar" que "compañera" de la Arqueología, la Informática, en su continuo desarrollo y en su carrera por ayudar a los humanos, ha llegado incluso a "devolvernos el guante" cuando puso a nuestro alcance una herramienta que, emulando los mecanismos del pensamiento humano, supone ahora un desafío para los ar- 
queólogos que pretendan intentar saber del Pasado algo más que lo que ellos mismos son capaces de deducir "jugando" con la información de que disponen y confiando solamente en su propio saber: la Inteligencia Artificial (IA).

Decíamos en páginas anteriores que, hablando en lenguaje figurado, el arqueólogo ha de formular a las UI una serie de "preguntas" a las presuntamente éstas deben "responder" en función de los datos que las constituyen, y precisamente una de las posibilidades que la Informática ofrece a la Arqueología, en su especialidad de IA, es la utilización de los denominados Sistemas Expertos, que permiten obtener "respuestas" para "preguntas" a las que las evidencias arqueológicas no pueden "contestar" por sí mismas.

En el llamado mundo de la Inteligencia Artificial, esos Sistemas Expertos suponen un área de creciente importancia en el desarrollo y aplicaciones de la Informática, un área de la que a nadie escapa que, como concepto, no equivale a un juego de soñadores ni de científicos excéntricos, que están convencidos de que el "cerebro electrónico" es capaz de realizar cualquier cosa y de llegar a actuar incluso como lo haría un ser humano, simulando su inteligencia, sino que se trata de un conjunto de desarrollos y aplicaciones de la ciencia de los Ordenadores, que están incidiendo notablemente, y con seguridad lo harán más en el futuro, en nuestra vida diaria y por tanto en nuestra propia Historia, que han provocado, provocan y provocarán profundos cambios en nuestra sociedad, la misma en que hoy actúa y se desarrolla la ciencia arqueológica.

Las técnicas de la IA son variadísimas y el campo de sus aplicaciones se extiende cada vez más en el ambiente tecnológico, científico y humanístico, y hablar de ella ha pasado de ser una expresión más o menos mitificada y llena de misteriosas sugerencias para los "no iniciados", a convertirse en una realidad tangible que se incorpora a áreas de trabajo cada vez más variadas, y en las que sus "inventores", los pioneros en su utilización y los defensores de su aplicación, ni siquiera soñaron.

Y si la IA es la ciencia que permite que los ordenadores emulen capacidades humanas tales como la de ver, oír, hablar e incluso las de manipular, elaborar y tomar decisiones, a partir de un conjunto preestablecido de analogías y deducciones, y como además, el ordenador permite hacerlo almacenando y procesando a enormes velocidades grandes cantidades de datos, es fácil pues comprender que la IA. puede convertir a estas máquinas en expertos "ayudantes" del Hombre en una gran variedad de campos del saber y de la actividad humanos al hacerlas funcionar, a semejanza de la mente humana, con esas "órdenes" que conocemos como programas de reconocimiento y proceso de formas e imágenes, de proceso del lenguaje humano, de robótica, de razonamiento abstracto, etc., programas que no son sino una emulación de lo que el Hombre hace cuando observa, habla, se mueve, razona, etc..
Hoy ya no resulta extraño que las técnicas de la IA se utilicen en la resolución de determinados problemas planteados en los campos de la Medicina, la Geología, la Ingenieria, la Física o la Química, y ni siquiera que podamos jugar no con un contrincante de nuestra especie que piense, planifique, deduzca y finalmente "mueva ficha" sino con una máquina que, sin pensar sensu stricto porque actúa en función de la información y las órdenes que se le han dado, sí lo haga, pero que esas técnicas se empleen para acercarse a la resolución de problemas de interpretación histórica como, por ejemplo los inherentes a los modelos y niveles de la economía prehistórica no resulta usual sino más bien excepcional, de forma que una sencilla búsqueda en Internet permite observar de inmediato cómo mientras las aplicaciones de otras técnicas de tratamiento y gestión de la información arqueológica son cada vez más frecuentes, sin embargo las de la IA no, tal vez porque los profesionales de la Historia, en general, y de la Arqueología, en particular, generalmente y salvo excepciones -que como en todo existen- se consideran suficientemente expertos como para conocer, analizar e interpretar la información del Pasado que ha llegado hasta nosotros, pese a que, como hemos visto, esa información es per se bastante problemática.

Ciertamente resultaría demasiado extenso comentar aquí las múltiples posibilidades que ofrece la IA a la Arqueología, pero ya que el fin primordial de este trabajo es acercar a los recientes y futuros profesionales de esa ciencia a los muchos problemas que plantea la información con la que de algún modo y en algún momento tendrán que "lidiar", vamos a referirnos ahora a dos manifestaciones de la IA que resultan altamente útiles para tratar y gestionar cierto tipo de información: los programas de reconocimiento de formas y los Sistemas Expertos.

\subsubsection{Reconocer, identificar, clasificar}

Como apuntamos en páginas anteriores, el conjunto de la información arqueológica a que el arqueólogo se enfrenta en las distintas fases y facetas de su trabajo, y la que él mismo genera, está constituido por una amplia y variada "gama" de UI cada una de las cuales es a su vez un compendio "variopinto y multicolor" de datos de diferentes características. Pues bien, concretamente los datos relativos a la propia morfología de los restos culturales, algo evidentemente necesario para identificar el tipo de resto de que se trata y poder establecer su clasificación cronocultural, último paso antes de interpretar su significado en el Pasado a que corresponde y en consecuencia su relevancia como documento histórico, a menudo no son fácilmente utilizables porque:

- o bien aun conociéndolos en su totalidad no permiten identificar esa morfología como "normal"/"esporádi- 
ca" en base a otros ejemplares similares, al ser demasiado reducido el $n^{\circ}$ de tipos formales conocidos de esa clase de restos culturales y/o al no ser posible la comparación física de los mismos, quizá por lo contrario, por su abundancia,

- o bien esa UI está incompleta y consecuentemente sus datos morfológicos también, circunstancia muy habitual, por razones obvias, ante restos y residuos, y no podemos olvidar que éstos son los restos culturales más abundantes de los que se ocupa la Arqueología.

Es más, hasta momentos muy recientes de la larga Historia de la Humanidad, hasta que tecnologías "avanzadas" permitieron la fabricación de objetos "en serie", el grado de variabilidad formal de los objetos fabricados por el hombre dependió de la capacidad de los distintos artífices para fabricar objetos sensiblemente iguales morfológicamente a los que ya servían para cubrir las correspondientes necesidades, para trabajar diferentes materias primas, para aceptar, adoptar, adaptar y en su caso copiar las innovaciones, etc. y por supuesto también, de su grado de virtuosismo y, en ocasiones, incluso de genialidad, todo lo cual supone que los muchos factores que confluyeron en la morfología de los objetos, también fueron los determinantes de que ciertas morfologías se repitieran de manera más o menos sistemática.

Ante este panorama es evidente que son muchos los casos en que resulta muy complicado, a veces casi imposible, identificar esa morfología, sobre todo cuando no se trata ni siquiera de objetos completos sino de fragmentos, en ocasiones mínimos por su tamaño o por corresponder a una mínima parte del todo, o lo que es lo mismo, que son muchos los casos en que los datos relativos a la morfología no suponen una información que ayude al arqueólogo, sino todo lo contrario.

Y es precisamente en esos casos en los que la IA ofrece la posibilidad de que el ordenador identifique automáticamente esa morfología mediante esos programas de reconocimiento de formas, programas que "conjugan" imágenes y algoritmos y que son capaces de identificar, p.e., la función matemática correspondiente a un determinado fragmento de curva, lo que permite reconocer la curva en cuestión y con ello identificar su correspondencia en una tipología mediante la búsqueda en la correspondiente BD en la que los componentes de esa tipología estén almacenados, de lo que se desprende que la única condición sine qua non para que esos programas ejecuten su tarea es que exista una BD de referencia. Al fin y al cabo, el ordenador, que bien puede estar manejado por una persona no experta o poco experta en la materia, al ejecutar uno de esos programas de reconocimiento de formas estará actuando como un experto humano que, bien conocedor de las características morfológicas de determinados tipos de objetos, por su saber y experiencia acumulados, sea capaz de reconocer, identificar, clasificar, etc. porque "almacena" y procesa (ordenando, jerarquizando, relacionando datos) la información que le permite hacerlo.

\subsection{2. "Expertos" para no expertos}

La extensa lista de problemas enunciados al comienzo de estas páginas en relación con la información arqueológica tal vez hayan inducido al lector a plantearse hasta qué punto el principiante puede ni siquiera intentar enfrentarse a ellos, cómo puede solventar situaciones que aqui se han planteado como verdaderos obstáculos no sólo para quienes inician su andadura como arqueólogos/as, sino incluso para todo el colectivo de profesionales de la investigación del Pasado, ya actúen como tales en el marco académico, o no.

Dicho de otra forma: es posible que el lector se esté planteando al llegar aqui que hace falta ser un verdadero experto de la Arqueología -y quizá esté pensando que también de la Informática- para poder trabajar con la propia información arqueológica.

Pero la realidad es muy distinta, ya que la Informática es una ciencia "generosa" que oferta soluciones a problemas generales, y trabaja para que la aplicación de las mismas resulte cada vez más fácil y cómoda para sus usuarios, y concretamente en su campo de la IA, para que puedan actuar sobre problemas "de alto nivel" incluso quienes por edad, formación y/o medios pudieran considerarse como mucho "conocedores de la cuestión" pero no "expertos" y pensar que las soluciones a esos problemas son para ellos inalcanzables.

Resumiendo la larga definición dada por la British Computer Society, un Sistema Experto (en adelante SE), es una de las aplicaciones de la Inteligencia Artificial, que pese a configurarse como una de las tecnologías más importantes para el futuro, y sobre todo en sus aplicaciones microinformáticas, no es más que un "simple" programa de ordenador dotado en su "arquitectura informática" de la experiencia humana en algún área o campo de conocimiento, y es capaz de hacer algo que solamente podría hacer un humano y, además, experto en la materia. Pues bien, esta sintética definición implica algo evidente: que la solución a los problemas depende de la información de que pueda disponer el programa y de que las reglas que pueda utilizar estén convenientemente diseñadas, es decir, elaboradas en base a un amplio y profundo conocimiento del tema, de todo lo cual se desprende que cuanta más información haya disponible -sean cuales sean sus caracteristicas- y cuanto más y mejor conocimiento del problema tenga quien confeccione el programa, éste será más amplia y más fácilmente utilizable y también serán mejores los resultados de su aplicación.

La información arqueológica disponible es abundante, pero muy variada y heterogénea ... y el conocimiento que la Arqueología tiene sobre el Pasado, a menudo no es ni muy 
completo ni demasiado "sólido", porque no solo depende de esa información, sino también del "uso" que hagamos de ellas, de cómo la interpretemos. En una palabra, ese conocimiento depende de la capacidad del arqueólogo para seleccionar la información relativa a determinados problemas que resulta útil para, relacionándola según la lógica humana, identificar "situaciones" y decidir cual es la respuesta más acertada para las incógnitas que éstos plantean, y es en esa tarea en la que los SE se convierten en "sabios" aliados del arqueólogo y, en definitiva, del historiador.

Es más, algunos de esos SE pueden incluso enfrentarse a una circunstancia prácticamente inherente a una ciencia tan "viva" como la Arqueología, y es que pueden trabajar con una información compuesta por datos cambiantes -sea cuantitativa o cualitativamente, porque se producen nuevos descubrimientos, o se identifican/plantean nuevos "valores" o significados para los mismos-, y con ello puede a su vez contribuir tanto a ampliar el volumen de esa información, detectando p.e. la existencia de nuevos yacimientos con determinadas características (del mismo modo que son capaces de detectar la existencia de agua, gases, minerales, etc.), como a elevar el nivel del propio conocimiento identificando "situaciones nuevas" que inmediatamente requieren nuevas hipótesis para su interpretación. $Y$ decimos que sólo algunos SE pueden hacerlo porque, si no están programados para avisar a quien esté operando con ellos, pueden resultar bastante "estúpidos" cuando se encuentran con algo que no encaja en el repertorio que tienen preprogramado: si no tienen la capacidad de ampliar su base de datos "sobre la marcha" y sólo pueden "pensar en línea recta" (de $A$ a $B$, de ahí a $C$, etc.), tampoco tienen modo de saber cuándo es inapropiado el conocimiento tan laboriosamente programado, es decir, no reconocen "la excepción a la regla".

La información, en general y la arqueológica en particular, es muy abundante, variada y heterogénea, pero además no está perfecta, ya que es evidentemente incompleta (no se conoce toda la necesaria para tomar decisiones totalmente seguras), de terminología imprecisa (diferentes términos con el mismo sentido, el mismo término con sentidos diferentes), con datos inciertos (no confirmados o conocidos imprecisamente) y de conocimiento también incierto (reglas no siempre válidas), y esto es algo de lo que hay que ser plenamente conscientes al plantearse la utilización de los SE, como también es preciso saber que el conocimiento, también en general, es de varios tipos entre los que destacan dos: el basado en la experiencia y el basado en la relación causa-efecto.

En el primer caso, el experto humano o la BD del SE correspondiente son simplemente "portadores de hechos acaecidos", hechos en los que está contenido el conocimiento pero de los que se desconocen las causas que han dado lugar a ellos, lo que hace que con frecuencia la información sea difusa o aleatoria y requiera un tratamiento especial. En el segundo, cuando el conocimiento es de tipo causa-efecto, consecuencia de una información más perfecta y obviamente más profundo que el anterior, entonces es posible utilizar la lógica clásica, el análisis es mucho más sencillo y el científico puede pensar que ha encontrado "la situación ideal", situación difícilmente alcanzable para la Arqueología, que al estudiar los restos culturales no hace sino estudiar los "efectos" pero que ha de intentar descubrir las "causas" y que consecuentemente puede inducir al profesional de esta ciencia a plantearse cuándo puede entonces utilizar esa herramienta que le ofrece la IA.

Pues bien, haciendo un ejercicio de pragmatismo, objetividad y, si es preciso, de humildad, hemos de admitir que en nuestro mundo el número de expertos sobre un tema específico es limitado, razón de más para tener en cuenta que un SE se hace valer cuando la persona experta no está presente pero sí lo están su pericia y/o su conocimiento del tema, o cuando ni siquiera la persona experta sabe la relación causal entre observaciones y resultados con un grado de certeza del cien por cien, condiciones ambas ciertamente frecuentes en distintas fases de actuación de la Arqueología, tanto para quienes tenemos ya cierta experiencia como para los que empiezan a adquirirla y, por frecuentes, sumamente propicias para hacer trabajar a alguno o algunos de esos sistemas con la información arqueológica.

La estructura de un programa experto responde a un simple esquema formado por dos bloques fundamentales: una "base de conocimientos" (la información contenida en una BD), y un "motor de inferencias" o bloque de deducción (núcleo del SE que contiene los algoritmos encargados de generar los razonamientos, y de los que existen en la actualidad más de un centenar de modelos).

Un "sistema experto" cuenta además, con un tercer bloque: el que se "comunica" con el usuario y que está encargado, mediante mensajes en la pantalla del monitor, de proporcionar aclaraciones (subsistemas de explicación 0 interface de usuario) y es capaz de simular la adquisición del conocimiento. La llamada "interfaz de usuario" es parte fundamental en toda la mecánica de construcción del "Sistema", ya que es lo que le convierte en verdaderamente utilizable por los "no expertos".

Como queda recogido en la Tabla 4 (basada, como las siguientes en CASTILLO, E. y ÁLVAREZ, E., 1989: Sistemas Expertos. Aprendizaje e incertidumbre. Ed. Paraninfo. Madrid), entre los diferentes tipos de SE destacan básicamente dos, cuyas caracteristicas son, en sintesis, las siguientes:

- SE basados en reglas, cuya base de conocimiento está constituida por un conjunto de reglas bien conocidas, $\mathrm{y}$

- SE basados en la probabilidad, que contemplan un espacio probabilistica en el que se incluyen los "sucesos" y sus "dependencias". 
Tabla 4

\begin{tabular}{|l|l|l|}
\hline \multicolumn{2}{|c|}{ COMPONENTES Y TIPOS DE SISTEMAS EXPERTOS } \\
\hline \multirow{2}{*}{ Elementos } & \multicolumn{1}{|c|}{ Modelo basado en reglas } & \multicolumn{1}{c|}{ Modelo probabilístico } \\
\hline \multirow{2}{*}{ Base de conocimiento } & Abstracto: reglas & Abstracto: Estructura probabilistica (sucesos dependientes) \\
\cline { 2 - 3 } & Concreto: hechos & Concreto: hechos \\
\hline Subsistema de explicación & $\begin{array}{l}\text { Encadenamientos hacia atrás y hacia } \\
\text { delante }\end{array}$ & $\begin{array}{l}\text { Evaluación de probabilidades condicionales } \\
\text { (Teorema de Bayes) }\end{array}$ \\
\hline \multirow{2}{*}{ Adquisición de conocimiento } & Basado en reglas activas & Basado en probabilidades condicionales \\
\cline { 2 - 3 } & Reglas & Espacio probabilistica \\
\hline \multirow{2}{*}{ Subsistema de aprendizaje } & Nuevas reglas & Parámetros \\
\cline { 2 - 3 } & Cambio en los factores de certeza & Cambio en la estructura del espacio probabilistica \\
\hline
\end{tabular}

Pues bien, como sintetizamos ahora en la Tabla 5, ambos presentan ventajas e inconvenientes, pero cabe destacar la rapidez del motor de inferencia en los modelos probabilísticas, debido a que en general están presentes en él todas las implicaciones y sólo se trata de determinar con qué probabilidad se da una implicación concreta; pero, en cualquier caso, son muchos los aspectos a tener en cuenta (Tabla 6), para plantear la utilización de SE en el ámbito de la Arqueología, porque son muchas las razones que así lo aconsejan, los beneficios que ello reporta, lo que aportan a la propia investigación arqueológica las diferentes etapas de su desarrollo, y mucha también la utilidad de la necesidad que plantean de determinar el tipo/s de su/s usuario/s una necesidad que a menudo contribuye a clarificar en buena medida el planteamiento de esos problemas en bien de su mejor comprensión.

Parece obvio que no precisa más explicación el beneficio que supone no sólo resolver problemas sin la participación de los expertos humanos, sino también conseguir un ahorro importante y multiplicar el número de posibles beneficiados del conocimiento -en muchos casos, la rapidez de obtención de soluciones es totalmente necesaria ya que sin esa rapidez las soluciones obtenidas serian inútiles-, así como el incremento de fiabilidad que se consigue gracias al tratamiento computerizado de datos, de forma que, atendiendo a todo lo expuesto hasta aquí, pensamos que también es obvio que el empleo de este tipo de "expertos" resul- ta especialmente recomendable en nuestra ciencia, la Arqueología, ya que, la mayor parte de las veces, de los hechos del Pasado no poseemos una imagen tan fidedignamente exacta que nos permita establecer reglas de lógica determinista, clásicamente "aristotélica", sino que más bien lo que poseemos de los tiempos pretéritos es una especie de conocimiento "difuso", que tiene un valor probabilístico alto o bajo según sea cada vez considerado el hecho bajo variadísimas circunstancias, incluidas las de ser conocido de forma incompleta.

A nivel de eficiencia y como aplicaciones arqueomáticas, más que los sistemas basados en reglas, es recomendable el uso de los modelos probabilisticas, y para plantear esta recomendación nos basamos ahora en nuestra propia experiencia personal en la utilización de Sistemas expertos que, basados en modelos aplicados en Medicina, nos han permitido abordar problemas relacionados con aspectos históricos tan difíciles de conocer como las economías de gentes que nos precedieron en cuatro y cinco milenios, trabajando con la hipótesis de partida o propuesta convencional de que los "actos y artefactos" que existen en los Yacimientos arqueológicos son a los fenómenos económicos, lo que en Medicina los síntomas a las enfermedades, hipótesis que permite construir una Base de Conocimientos formada por una serie de preguntas referidas a la identificación (como sintomas) de resultados (como enfermedades) de carácter económico. Es decir, se supone que si en un yacimiento arqueológico

Tabla 5

\begin{tabular}{|l|l|l|}
\hline \multirow{2}{*}{ Ventajas } & \multicolumn{1}{|c|}{ Modelo basado en reglas } & \multicolumn{1}{c|}{ Modelo probabilístico } \\
\hline \multirow{2}{*}{ Defectos } & Fácil explicación & Motor de inferencia rápido \\
\cline { 2 - 3 } & \multirow{2}{*}{ Sólo implicaciones deseadas } & Fácil aprendizaje paramétrico \\
\cline { 2 - 3 } & & Fácil propagación de incertidumbre \\
\hline & Motor de interferencia lento & Número de parámetros elevado \\
\cline { 2 - 3 } & Dificultad de propagación deincertidumbre & Implicaciones superfluas \\
\hline
\end{tabular}


Tabla 6

\begin{tabular}{|c|c|c|c|}
\hline Razones & Beneficios & Etapas de desarrollo & Tipos de usuarios \\
\hline $\begin{array}{l}\text { Posibilidad de utilizar personal } \\
\text { no especializado para resolver } \\
\text { problemas que requieren } \\
\text { especialización }\end{array}$ & Adquirir conocimiento & 1. Definición del problema & $\begin{array}{l}\text { Usuario de un experto } \\
\text { desarrollado por otro }\end{array}$ \\
\hline $\begin{array}{l}\text { Obtención de soluciones más } \\
\text { rápidas }\end{array}$ & Almacenar conocimiento & $\begin{array}{l}\text { 2. Búsqueda de un experto } \\
\text { humano/datos/experiencia }\end{array}$ & $\begin{array}{l}\text { Usuario de una "concha" con la } \\
\text { que sólo aporta la bases del } \\
\text { conocimiento }\end{array}$ \\
\hline $\begin{array}{l}\text { Obtención de soluciones más } \\
\text { fiables }\end{array}$ & Razonar e inferir & 3. Diseño del sistema & $\begin{array}{l}\text { Usuario que utiliza una } \\
\text { herramienta con la que } \\
\text { implementa un motor de } \\
\text { inferencia e incorpora la base } \\
\text { de conocimiento }\end{array}$ \\
\hline Reducción de costes & $\begin{array}{l}\text { Demandar nueva } \\
\text { información }\end{array}$ & $\begin{array}{l}\text { 4. Elección grado de } \\
\text { intervención de usuario }\end{array}$ & $\begin{array}{l}\text { Usuario que utiliza un lenguaje } \\
\text { de alto nivel (LISP, PROLOG, C, } \\
\text { PASCAL, etc.) }\end{array}$ \\
\hline $\begin{array}{l}\text { Eliminación de operaciones } \\
\text { incómodas y monótonas }\end{array}$ & Aprender & $\begin{array}{l}\text { 5. Elección de la herramienta, } \\
\text { "concha" o lenguaje de } \\
\text { desarrollo }\end{array}$ & \\
\hline Escasez de expertos humanos & Propagar incertidumbre & 6. Desarrollo de un prototipo & \\
\hline $\begin{array}{l}\text { Acceso del conocimiento a } \\
\text { poblaciones más amplias }\end{array}$ & $\begin{array}{l}\text { Asistir al experto a dar } \\
\text { información coherente }\end{array}$ & 7. Prueba de prototipo & \\
\hline $\begin{array}{l}\text { Los expertos son dificilmente } \\
\text { accesibles }\end{array}$ & Explicar las conclusiones & $\begin{array}{l}\text { 8. Refinamiento } \\
\text { y generalización }\end{array}$ & \\
\hline Los expertos son muy caros & $\begin{array}{l}\text { Actuar como consecuencia } \\
\text { del razonamiento }\end{array}$ & 9. Mantenimiento & \\
\hline $\begin{array}{l}\text { Es preciso mejorar el } \\
\text { conocimiento }\end{array}$ & $\begin{array}{l}\text { Controlar la coherencia del } \\
\text { conocimiento del sistema }\end{array}$ & & \\
\hline \multicolumn{4}{|l|}{$\begin{array}{l}\text { El conocimiento es difícil } \\
\text { de adquirir y se basa en las } \\
\text { reglas que sólo la experiencia } \\
\text { da a conocer }\end{array}$} \\
\hline \multicolumn{4}{|l|}{$\begin{array}{l}\text { La información disponible } \\
\text { es pobre, parcial, incompleta } \\
\text { o los problemas están mal } \\
\text { definidos }\end{array}$} \\
\hline \multicolumn{4}{|l|}{$\begin{array}{l}\text { Hay desconocimiento general } \\
\text { entre los que necesitan el } \\
\text { conocimiento }\end{array}$} \\
\hline $\begin{array}{l}\text { El problema está condicionado } \\
\text { por normas legales muy } \\
\text { cambiantes }\end{array}$ & & & \\
\hline
\end{tabular}

aparecen elementos (sintomas) vinculables a las tareas agrícolas tales como objetos empleados para la roturación, ejemplos de cereales, útiles de molturación, recipientes o estructuras de almacenaje, etc., existe indudablemente un modelo económico en el que de algún modo ha jugado un papel más o menos importante la agricultura (enfermedad), y la valoración aritmética del binomio cualitativo/cuantitativo del ob- jeto/testimonio (síntoma), permitirá identificar el nivel de ese grado de economía (levedad o gravedad de la enfermedad), siguiendo el símil médico propuesto.

Así, dado que poder precisar con exactitud el valor gradual que las diferentes "economías" alcanzan en la Protohistoria y el nivel logrado por cada uno de esos "grados» en relación con las actividades que los condicionan, resulta algo 
bastante complicado de considerar y de exponer, entendiendo esa consideración y exposición de la forma más objetiva posible, un programa "preparado por un experto" en, por ejemplo, Economía de la Edad del Bronce, sirve a un "no experto" ya que, en forma interactiva, el programa preguntará desde el Ordenador a su interlocutor todas, o solamente algunas de las preguntas de un cuestionario en relación con actividades o restos de la vida económica del asentamiento que se analiza, directa o indirectamente representados en forma de actos o artefactos, sin olvidar la propia realidad arqueológica del Yacimiento en lo que a su ubicación topográfica, organización estructural, etc., se refiere, y una vez hecha la pregunta, el ordenador espera una respuesta afirmativa o negativa para efectuar los cálculos.

Con todo, y aunque es cierto que venimos recomendando el empleo de estas nuevas técnicas de tratamiento de la información arqueológica desde hace casi dos décadas, no olvidamos en ningún momento que sus aplicaciones y los métodos que algunos de los programas más actuales conllevan, tienen que seguir siendo considerados con cierta precaución y, sobre todo, aplicados con exquisita prudencia, adaptándonos en cada ocasión a la naturaleza del tema para cuyo estudio se utiliza.

\section{EL FINAL DE LA “CADENA OPERATIVA": SISTEMAS INTEGRADOS DE INFORMACIÓN ARQUEOLÓGICA (SIA)}

Localizar, elaborar, almacenar, gestionar, estudiar, interpretar y prepararla para su presentación y/o publicación son operaciones que el arqueólogo debe realizar con la información que maneja y genera para que los frutos de su trabajo sean finalmente útiles a la Historia, y parece evidente que hoy es innegable la gran ayuda que las tecnologías de la información ofrecen para conseguirlo, y tanto es así que si hasta hace poco se incluia la Informática entre las Ciencias y Técnicas "auxiliares" de la Arqueología, ahora debería situarse entre las imprescindibles para que ésta ocupe el lugar que le corresponde como método de la Historia, y más concretamente aún, como único método para reconstruir la de, con diferencia, la mayor parte de la Historia de la Humanidad, no sólo porque los documentos escritos aparecieron hace apenas 5.000 de los más de 4.000 .000 de años que, por lo que sabemos, lleva el Hombre sobre la Tierra, sino porque en muchos casos es la Arqueología la que ayuda a comprender éstos y a completar la información que ellos mismo contienen.

Pero también parece evidente que ciertas aplicaciones informáticas ofrecen la posibilidad no sólo de solucionar los problemas "puntuales" que se nos presentan en cada una de esas fases o facetas de la actividad arqueológica, sino también de plantearnos un modo de trabajo más sistemático, una metodología que contemple la necesidad de optimizar la inversión de tiempo y esfuerzo en función de una obtención de resultados lo más rápida posible, y qué duda cabe de que esto es posible, o al menos se puede intentar que lo sea, si "sistematizamos" nuestras propias ideas y nuestro propio trabajo y nos planteamos que del modo de almacenaje de la información puede depender que luego sólo se pueda gestionar de una manera, o de varias, es decir, que almacenada de una determinada forma pueda ser útil sólo para una o también para varias aplicaciones, y este planteamiento evidentemente obliga a conocer la información y a tener claro qué queremos hacer con ella y, sobre todo, qué queremos obtener de ella.

Este planteamiento, que supone utilizar Bases de Datos que puedan ser además de "almacenes" de información en los que guardar, ordenar, modificar, actualizar, buscar, seleccionar, etc. los datos, también "plataformas" de actuación de Sistemas de Información Geográfica y de aplicaciones de Inteligencia Artificial, supone así mismo plantearse la posibilidad de organizar y utilizar un verdadero Sistema Integrado de Información Arqueológica (SIA), lo que indefectiblemente obligaría a unificar criterios, objetivos y metodologías, pero lo que sin duda supondría a su vez economizar esfuerzos que ahora mismo se multiplican innecesariamente, y tanto en el plano científico como en otro, más práctico pero de mayor proyección, como lo es el ámbito de actuación de las Administraciones públicas en su actividad de gestión del Patrimonio Cultural, y supondría también una mayor y más rápida participación de los descubrimientos y avances de la propia Arqueología y de sus actuaciones, ya que facilitaría, entre otras cosas, la incorporación de datos arqueológicos a Infraestructuras de Datos Espaciales (IDE), incluso en tiempo real.

\section{Y UN PUNTO DE PARTIDA A MODO DE CONCLUSIÓN}

Seguramente sería de esperar que las últimas líneas de este artículo fuesen no una sintesis de lo expuesto, porque pensamos que, de ser más sintético aún seria también más incomprensible para los lectores a quienes va especialmente dirigido, estudiantes y futuros profesionales de la Arqueología, sino una conclusión en la que quedase claramente reflejada la respuesta a la pregunta planteada en el título del trabajo, qué supone realmente la información para el arqueólogo, un problema o un reto.

Pues bien, parece que no habrá conclusión porque, desde nuestra óptica, la respuesta es que "ambas cosas a la vez": un problema al que hemos de enfrentarnos y un reto porque de la solución que le demos depende en buena medida el éxito de nuestro propio quehacer científico y profesional, y el reto está en aceptar que las tecnologías de la información nos ofrecen no sólo soluciones para el problema, sino tam- 
bién muchas y nuevas posibilidades de sacar el máximo partido de una información compuesta por datos "mudos", que no "dicen" nada pero que son evidencia de mucho, y aceptado esto, indudablemente es también un reto el aprender a utilizar esas tecnologías y aplicarlas, algo que hoy aún nos resulta ciertamente costoso a quienes nos hemos formado en el mundo de las Humanidades, por supuesto a unos más que a otros, pero que sabemos presentará muchas menos dificultades a las generaciones futuras.
Por todo ello no podemos llegar a otra conclusión que la de esperar que lo que aqui se ha planteado como un dilema, en adelante no lo sea, y que estas páginas sean sin embargo para quienes las lean un punto de partida en alguna etapa de su formación y/o de su vida profesional o, en su caso, un rayo de luz que ilumine algo más los conocimientos adquiridos a lo largo de su formación académica. 